\title{
It Takes More than Two to Tango: Identifying Roles and Patterns in Multi-Actor Smart Service Innovation
}

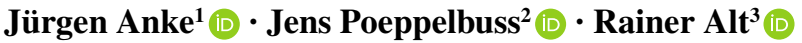

Received: 31 October 2019 / Accepted: 18 August 2020 / Published online: 15 September 2020

(C) The Author(s) 2020

\begin{abstract}
Smart service systems enable innovative value propositions based on smart products and data-driven value creation. Grounded in service-dominant logic as our theoretical lens, we argue that smart service innovation takes place in ecosystems of collaborating actors, as a single actor does not possess all required resources and competencies. We empirically explore smart service innovation using an interview study of 14 experts who were involved in real-world smart service systems engineering projects. As a result, we conceptualize 17 roles that describe the resources and competencies required for smart service innovation at an abstract level. Through the analysis of actor-role constellations in our sample of projects, we further identify four patterns that exhibit different strategic approaches to smart service innovation. Our results advance the theoretical understanding of smart service systems through an empirically grounded systematization of roles, which reflect the resources and competencies required for smart service innovation. With this study, we shed light on the multi-actor and inter-organizational settings of service innovation processes, which have been under-researched so far. Our insights are further helpful for practitioners, who participate in the smart service innovation and who need to analyze their strategic position in service ecosystems.
\end{abstract}

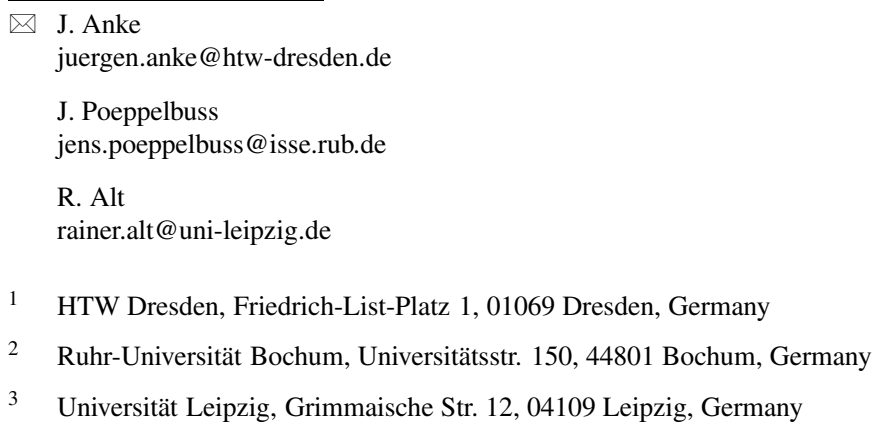


Keywords Smart service systems - Service ecosystems - Roles - Service-dominant logic $\cdot$ Inter-organizational projects $\cdot$ Service systems engineering

JEL codes $\mathrm{M} 15 \cdot \mathrm{L} 86 \cdot \mathrm{O} 32 \cdot \mathrm{O} 30$

\section{Introduction}

In today's digitally connected world, more than ever, service innovations result from the interactions between multiple actors. While we have traditionally seen the service provider as a rather independent actor in the driver's seat of service innovation processes, we now recognize that these firms require an increasing amount of help from external actors to successfully develop new digitally-enabled value propositions and corresponding resource integration mechanisms within their service ecosystems. Especially smart service systems, which enable value propositions based on smart products and data-driven value creation, illustrate that resources and competencies from a whole network of actors are required to put them in place. A narrow focus on dyads of service providers and customers with static roles is not adequate anymore - if it ever has been. Hence, it takes more than two to tango as digital technologies bring new actors into play who are, amongst others, specialized in systems integration, user interface design, cloud computing, data analytics, and platform business.

The value proposition of a smart service system is "preemptive in its behavior, adaptive to customer needs and contexts, thereby exceeding traditional offerings concerning both perceived customer value and provider efficiency" (Beverungen et al. 2019a, p. 1201). Smart products have been conceptualized as a constituent component of smart service systems (Beverungen et al. 2019b) as they can sense their condition and surroundings, allow for real-time data collection, continuous monitoring and communication, remote control and interactive feedback (Allmendinger and Lombreglia 2005; Wuenderlich et al. 2015). Smart service systems already exist in various industries including manufacturing, logistics, mobility, and healthcare as well as in private living (Beverungen et al. 2019a). Examples include performancebased contracting for aircraft engines and industrial compressors in business-tobusiness (B2B) settings as well as home automation and driving-behavior-aware car insurances in business-to-consumer (B2C) settings.

It is evident from these examples that digital technologies are important enablers and drivers of service innovation through smart service systems (Nambisan 2013; Lusch and Nambisan 2015; Beverungen et al. 2019a). They are also a key reason why corresponding smart service systems engineering projects increasingly involve multi-actor collaboration because the required knowledge and expertise on the use of digital technologies and the access to digital infrastructures are often not fully available by a single actor (Porter and Heppelmann 2015; Ekman et al. 2016; Floerecke and Lehner 2016; Sklyar et al. 2019b). Furthermore, the use of digital technologies in smart service systems often goes hand in hand with structural changes to business models that affect the relationship and interaction with customers as well as the nature of value capture through revenue streams, e.g., pay-per-use and subscription 
payments instead of transaction-based product and service sales (Abrell et al. 2016; Storbacka et al. 2016; Chowdhury et al. 2018; Jussen et al. 2019). Therefore, incumbent actors also frequently need support from external actors in service innovation processes to envision and implement such changes in their network with customers, partners, and other actors.

The service-dominant (S-D) logic provides an appropriate theoretical lens to analyze multi-actor service innovation processes (Vargo and Lusch 2004; Ekman et al. 2016). According to S-D logic, actors do not develop services, but "they design and communicate new value propositions [and] develop and manage service systems capable of realizing the new value propositions" (Edvardsson and Tronvoll 2013, p. 21). S-D logic conceptualizes all market participants as generic actors who are involved in actor-to-actor (A2A) exchanges. Service innovation is understood as a collaborative process occurring in networks of actors, which are also referred to as service systems or service ecosystems (Edvardsson and Tronvoll 2013; Vargo and Lusch 2016). During service innovation, actors of the service ecosystem reconfigure their diverse resources and change institutional arrangements to provide new value propositions. (Edvardsson and Tronvoll 2013; Lusch and Nambisan 2015; Edvardsson et al. 2018). Ekman et al. (2016) further illustrate that the actors do not assume static roles (like customers or providers) but may assume several roles simultaneously and also actively change roles in the network of actors over time.

In line with S-D logic, we understand service innovation as the overall process from initiating the development of a new value proposition with an initial idea to its successful commercialization in the market. In this process "firms have a coordinating role" (Edvardsson et al. 2018, p. 90) and possess agency. They use their available resources, creativity, and strategic intent to initiate and create new value propositions. In our context of smart service systems, we refer to smart service innovation for the overall process from the first idea to market diffusion and smart service systems engineering (SSSE) for the deliberate activities of actors that aim at realizing new value propositions (Böhmann et al. 2014; Demirkan et al. 2015; Beverungen et al. 2018). SSSE is often organized in projects to consider cost, time, and quality as constraints. Such SSSE projects, which we consider to cover the "realizing" state of service innovation (Edvardsson et al. 2018, p. 98), are the unit of analysis in this study. In particular, we are interested in the various roles that actors assume in these projects as those reflect the necessary resources and competencies that are required to realize smart service systems. We also expect them to make institutional arrangements and strategic dependencies between actors visible.

Existing service research provides already some insights into multi-actor constellations in service ecosystems and service innovation (Ekman et al. 2016), but is very limited as regards the collaboration of actors in SSSE projects in particular. Studies of value co-creation between actors in technology-enabled service systems mostly examine existing and operational service systems (e.g., Breidbach and Maglio 2016), but do not address the projects in which such smart service systems are developed in the first place. Correspondingly, Dreyer et al. (2019) identify customer involvement in the engineering, operation, and improvement of smart service systems as a still under-researched field. They also show that the integration of further actors (e.g., partners or suppliers) has not even been discussed in the context of smart service 
systems. Furthermore, existing research seems to disregard that smart service systems can provide new entrants holding distinct resources (e.g., IT firms) with the opportunity to change institutional arrangements in service ecosystems fundamentally. That is, IT firms might not only engage in exchange relationships as a supplier of digital technologies but instead initiate and drive the development of innovative smart service value propositions themselves. Examples include Deutsche Telekom's smart parking solution "Park \& Joy"1 and the connected car platform "Drive" by AT\&T that leapfrog municipalities and automobile OEMs.

Therefore, we intend to advance our understanding of multi-actor smart service innovation through this qualitative-empirical interview study, which is grounded in S-D logic. In particular, we contribute through the analysis of actor-role constellations in SSSE projects. In this study, we pursue the following research questions:

- RQ1: Which roles are assumed by the different actors involved in SSSE projects?

- RQ2: Which different actor-role constellations can be identified in SSSE projects that reflect different patterns of smart service innovation?

Based on the data from interviews with 14 experts, we develop a set of roles that different actors assume in SSSE projects. Our study investigates actors at an organizational level and conceptualizes their distinct contributions (in terms of resources and competencies) as roles. With a dedicated focus on the SSSE projects, the formation process of the underlying A2A relationships is out of scope, as we consider these to be highly path-dependent with determining factors that go beyond single projects (Sydow 2009; Aaltonen et al. 2017). Furthermore, we do not analyze the "outcoming" state of service innovation that follows after the completion of the SSSE project (Edvardsson et al. 2018). Hence, the set of roles that we contribute reflects the resources and competencies that the realization of smart service systems requires.

Besides the conceptualization of roles, we also uncover their assignment to actors and thereby explain the division of labor in SSSE projects. It becomes visible which contributions are frequently sourced from actors that are external to the focal service provider. Finally, the analysis of the different actor-role-assignments across the SSSE projects allows us to derive smart service innovation patterns that reflect distinct strategies of utilizing and changing institutional arrangements in the service ecosystem. With our study, we contribute to the "clear priority" for theoretical and empirical research on smart service systems, which have so far mainly been envisaged from a practical and descriptive perspective (Djellal and Gallouj 2018, p. 17).

The remainder of this paper is organized as follows. In Sect. 2, we introduce the theoretical background with key concepts related to S-D logic and smart service systems, as well as actors and roles in service innovation and business ecosystems. Then, we explain our research method in Sect. 3. Sect. 4 presents our findings from the interviews, including the proposed conceptualization of roles in SSSE projects

\footnotetext{
1 https://www.parkandjoy.de/.

2 https://drive.att.com/.
} 
and actor-role constellations, which explain different smart service innovation patterns. The paper closes with a discussion (Sect. 5) and conclusions (Sect. 6).

\section{Research Background}

\subsection{Service Innovation with Smart Service Systems}

In this study, we adopt the service-dominant (S-D) logic as our theoretical grounding of service and service innovation. In S-D logic, service is understood as the process of using one's resources, including specialized competencies like knowledge and skills, for the benefit of another actor or the actor itself (Vargo and Lusch 2004; Lusch and Vargo 2016). S-D logic also distinctively uses the singular term service to denote the process character of doing something beneficial instead of the plural term services that would imply units of output and, hence, a goods-dominant logic (Lusch and Nambisan 2015). Furthermore, the S-D logic does not distinguish between producers and consumers but adopts a generic A2A perspective on value exchange that dispenses with such pre-designated roles (Vargo and Lusch 2011; Lusch and Vargo 2016). Following this argument, "all actors fundamentally do the same things: integrate resources and engage in service exchange, all in the process of cocreating value." (Vargo and Lusch 2016, p. 7).

Service innovation refers to the reconfiguration of resources or changes in structures and value-co-creation processes of the service system (Vargo et al. 2010; Edvardsson and Tronvoll 2013), which lead to new practices that are useful and, hence, valuable, to actors in a specific context (Edvardsson and Tronvoll 2013; Lusch and Nambisan 2015; Edvardsson et al. 2018). Thus, when service firms (or more generally: actors) innovate, they design resource integration mechanisms, which are supposed to support other actors (e.g., customers) in integrating and acting on available resources so that they can create value in new and better ways. This also means that service firms do not develop services (as units of output), but, according to the $\mathrm{S}-\mathrm{D}$ logic, design and communicate new value propositions and develop and manage service systems.

Such a service system lens is appropriate for studying service innovation as it goes beyond traditional perspectives that are grounded in technological product inventions (Edvardsson and Tronvoll 2013). A system perspective further implies that "value creation takes place within and between systems at various levels of aggregation" (Vargo and Lusch 2008, p. 5). While there are different conceptualizations of these levels, it appears meaningful to distinguish between direct exchange among dyads of actors (reflecting a micro-context) and direct and indirect exchanges in more complex constellations (e.g., triads and networks) of actors (reflecting a meso- or macro-context) (Chandler and Vargo 2011; Ekman et al. 2016). Vargo and Lusch (2016) also use the term service ecosystem to describe such networks of actors. Hence, to understand service innovation, S-D logic requires us to pay attention to the multiple actors, resources, and institutional arrangements at different levels instead of only focusing too narrowly on innovative offerings or the innovation process (Edvardsson et al. 2018). 
Digital technologies provide multifaceted potentials for service innovation because operant resources such as information, skills, and knowledge can be combined and exchanged in novel ways that create value for the actors involved (Edvardsson and Tronvoll 2013; Nambisan 2013; Barrett et al. 2015; Sklyar et al. 2019a; Wolf 2020). Digital technologies "liquefy and distribute resources" through the A2Anetwork of a service system and also allow actors to "increase resource density to quickly access and utilize resources needed for service exchange" (Barrett et al. 2015, p. 143).

We increasingly refer to smart service systems when digital technologies are combined with individuals and organizations to share resources and co-create value (Djellal and Gallouj 2018). In smart service systems, smart products are a key digital technology that increasingly becomes part of changed, new, and useful valuecreating systems. Smart products refer to physical objects with embedded systems, sensors and actuators, and networking capability that enable learning, decisionmaking and dynamic adaptation to usage situations based upon data received, transmitted, and/or processed (Allmendinger and Lombreglia 2005; National Science Foundation 2014). Smart products can be conceptualized as boundary objects that integrate the resources and activities of actors in service systems (Beverungen et al. 2019 b), and, thus, enable the co-creation of smart service. Accordingly, the "attribute smart [...] highlights that digital technology allows for the transformation of service systems into smart service systems." (Beverungen et al. 2019a, p. 1202). Digging deeper into the distinctive attributes of smart services and their relationship to smart products, Boukhris and Fritzsche (2019) derive five dimensions that impact the "smartness of services", including the richness of data, the knowledge-intensity of the decision support engine, the level of sophistication of the outcome delivered to the beneficiaries, the architecture of the stakeholders, and the automation level of processes.

Despite the many works that put digital technologies and smart products center stage and push relevant social structures into the background, Beverungen et al. (2019a, p. 1202) posit that "smart service systems need to be understood as complex, open, and dynamic sociotechnical systems." Correspondingly, we see the need to better understand the interplay between people, organizations, and technology along with the different states of the system. In particular, we are interested in those actors that deliberately change service systems through service innovation, or smart service innovation to be more precise.

\subsection{Actors and Roles in Service Innovation}

It has already been argued that service innovation no longer originates from within a single organization, but rather evolves from "a network of actors" (Lusch and Nambisan 2015, pp. 155-156). Put differently, actors recombine elements from both internal and external resources for service innovation (Beverungen et al. 2018). Accordingly, Edvardsson et al. (2018, p. 99) conceptualize service innovation as a phenomenon that takes place in service ecosystems, which are defined as "relatively self-contained, self-adjusting system[s] of resource-integrating actors connected by shared institutional arrangements and mutual value creation through service ex- 
change." (Vargo and Lusch 2016, pp. 10-11). The service ecosystem perspective emphasizes that service innovation is a "phenomenon embedded in social structures and taking place within social systems, in which actors adopt certain social positions and roles to interact and recreate social structures" (Edvardsson and Tronvoll 2013, p. 20).

Generally, roles can be understood as "distinct technologically separable, value added activities undertaken by firms or individuals" (Kambil and Short 1994, p. 10) that reflect "clusters of behaviors expected of parties in particular statuses or positions" (Knight and Harland 2005, p. 282). Role theory usually assigns roles to individuals (Janowicz-Panjaitan and Noorderhaven 2009; Rese et al. 2013), but they can also apply to other actors such as teams, groups, organizations, or networks (Knight and Harland 2005; Avelino and Wittmayer 2016). This is also in line with S-D logic, where the generic actor can refer to any kind of economic and social entity like, e.g., firms, individuals, households, or nations (Lusch and Vargo 2006; Vargo and Lusch 2008).

While the S-D logic conceptualizes actors as generic, it does certainly not mean that all actors are identical (Vargo and Lusch 2016). It is mainly that the S-D logic refrains from assigning predesignated roles like producers and consumers to actors. Instead, it encourages us to characterize actors "in terms of distinctly constituted identities associated with unique intersections of the institutional arrangements, with which they associate themselves." (Vargo and Lusch 2016, p. 7) Moreover, actors can assume multiple roles simultaneously and the assumption of roles can be subject to dynamic changes over time (Ekman et al. 2016).

To better understand the distribution of roles in service ecosystems and across different states of service innovation, Ekman et al. (2016) present a typology of generic actor roles that distinguishes between provider and beneficiary roles as well as between active and passive roles, all of which can be assumed by different actors simultaneously. They further see the possibility of inactive actors in the wider service network, who "decline or ignore the invitation to cocreate and hence choose not to participate" (Ekman et al. 2016, p. 52). Ekman et al. (2016) also conceptualize an initiator role that triggers service innovation within a service ecosystem. The actors who hold this role give the initial "invitation to co-create" by engaging in "new service development as a means to be able to offer a new value proposition" (Ekman et al. 2016, p. 54).

Also grounded in S-D logic and specifically considering the collaboration of internal and external stakeholders as actors in service innovation, Jonas and Roth (2017) conceptualize a continuum of four modes of stakeholder integration. This continuum ranges from low to high stakeholder integration with the four modes of (1) passive integration, (2) reactive integration, (3) mutual integration, and (4) proactive initiative. Their empirical results from case studies (Jonas et al. 2016; Jonas and Roth 2017) exhibit higher degrees of integration almost only for stakeholders internal to the focal organization (e.g., top management). As regards external stakeholders, they find that it is mainly the customers and users who are (only passively or reactively) integrated at the very beginning (e.g., interviews) and the very end (e.g., testing) of the innovation process, especially by the service providers' sales 
personnel. They only see very limited evidence for the integration of other external stakeholders at all, including, e.g., suppliers and external service providers.

Finally, the S-D logic not only argues for an A2A perspective, but also for a dynamic view of service innovation (Edvardsson et al. 2018, p. 87). Correspondingly, Edvardsson et al. (2018) distinguish between three states of the service innovation process, including initiating, realizing, and outcoming. The initiating state mainly focuses on formulating intended value propositions so that they are attractive to potential customers and other actors. The realizing state is about putting the innovative value proposition into practice. The outcoming state refers to market diffusion and scaling up so that innovative value propositions become sustainable and the service providing actors can capture enough value to ensure their sustainability. Similarly, Ekman et al. (2016) illustrate the dynamic development of actor and role constellations from initial new service development via pilot implementations and service diffusion to network evaluation and service refinement. In their method for recombinant service systems engineering, Beverungen et al. (2018) distinguish between the three phases of service system analysis, design, and transformation.

Although service ecosystems can be understood as being subject to continuous reconfigurations because the different actors can change roles and resource configurations at any time, the existing conceptualizations and case studies following S-D logic still indicate that service innovation (or new service development) is typically conducted as a deliberate initiative that mainly covers the initiating and realizing state. That is, an actor initiates the service innovation endeavor (in the initiating state) and then sets up a dedicated project for designing the value proposition (in the realizing state). The project will usually involve various internal stakeholders (Jonas et al. 2016) but can also explicitly rely on contributions from external actors (Ekman et al. 2016; Beverungen et al. 2018). In the latter case, Sydow and Braun (2018) also use the term inter-organizational projects (IOPs) for those projects that are carried out in inter-organizational teams.

\subsection{Roles in Innovation and Business Ecosystems}

Apart from works grounded in S-D logic, there are further contributions from other research streams, especially innovation and business ecosystems, which conceptualize roles and develop ecosystem models. Dedehayir et al. (2018), for instance, conceptualize roles during the preparation, formation, and operation of innovation ecosystems, which they broadly define as "heterogeneous constellations of organizations, which co-evolve capabilities in the co-creation of value" (Dedehayir et al. 2018 , p. 2). They present four groups of roles with eleven roles in total, including (1) leadership roles (e.g., Ecosystem Leader), (2) direct value creation roles (e.g., Supplier and User), (3) value creation support roles (e.g., Expert), and (4) entrepreneurial ecosystem roles (e.g., Entrepreneur and Sponsor).

With a strong focus on the digital technologies that are also potentially relevant for smart service systems, we find additional and rather specific ecosystem models that devise roles, too. Papert and Pflaum (2017) present an ecosystem model with 19 roles for the realization of Internet of Things (IoT) services in a supply chain management context. They further structure their ecosystem into a central part, 
which includes the Solution Integrator as a key role, and two sub-systems for applications (including roles such as Application Developer and Middleware Provider) and smart products (including roles such as Product Manufacturer and Embedded System Provider). Floerecke et al. (2020) developed and revised the Passau Cloud Computing Ecosystem Model (PaCE), which comprises 31 roles for market actors, grouped into the five categories of client (End Customer), vendor (e.g., Network Operator), hybrid (e.g., Service Integrator), support (e.g., Training Provider), and environment (e.g., Legislator). Riasanow et al. (2020) analyzed the similarities of digital ecosystems in the automotive, blockchain, financial, insurance, and industrial IoT industries using conceptual modeling and large-scale cluster analysis. They define generic roles for each of the five industry-specific ecosystems and identify a core cluster of roles that are common across all five industries. This core cluster includes organizations that provide cloud infrastructure, platform and application services as well as data protection and security services.

These ecosystem models generally take a broader view on ecosystems and cover all the roles that generally exist in a specific industry or technology-centered ecosystem. However, they do not dedicate their attention to the specific roles of actors involved in service innovation when jointly designing a new value proposition in SSSE projects. Following Adner (2017), we also conclude that they rather take the view of "ecosystem-as-affiliation", which focuses on actors, as compared to "ecosystemas-structure", which focuses on the activities that need to be "undertaken in order for the value proposition to be created" (Adner 2017, p. 44).

\section{Methodology}

\subsection{Data Collection}

To investigate the roles of the multiple actors that engage in smart service innovation, we conducted an interview study. As there still is a need for more theoretical and empirical work on smart service systems in general (Djellal and Gallouj 2018) and we consider existing insights into the interaction of multiple actors during SSSE projects as very limited, we infer that a qualitative study that intends to build and extend theory is an appropriate research strategy.

In our study, we interviewed experts who were involved in real-world smart service innovation processes. The experts represent actors on both the level of the human individual and the level of the firm that they work for. During the interviews, we expected them to provide us with insights into a specific service ecosystem that they and their organizations were involved in. In particular, we were interested in the roles that the different actors enacted during SSSE projects. We intended to generate information-rich data and to capture a multiplicity of perspectives on practices, experiences, and challenges in service innovation processes.

To identify appropriate experts, we followed a purposive, theoretical sampling approach (Eisenhardt 1989; Yin 2016). We as researchers approached those people in our wider personal network from whom we expected to learn about interesting and relevant practical experiences that they had made in smart service innovation 
processes. Hence, we selected those from whom we knew that they deal with the realization of smart service systems. However, we first learned about the exact SSSE projects during the interviews and the experts were free to choose about which projects they wanted to provide detailed information. Hence, we did not select experts based on specific project characteristics. We also deliberately refrained from interviewing fellow researchers as we were interested in the role constellations and dynamics from real-world service innovation processes. When approaching the experts, we sought for variety within our sample, including experts with different positions (e.g., consultant or project manager) from different types of organizations (e.g., service providers and IT consultancies) and various industries with both B2C and B2B settings. Thereby, we intended to cover different actor perspectives, e.g., actors that we expected to be initiators and drivers of service innovation as well as further actors that were involved as less active subcontractors or similar. We continued our data collection until we as research team jointly gained the impression of a sufficient theoretical saturation; that is, we felt it unlikely to learn about fundamentally new types of actors and roles through continuing with further interviews. In the end, we interviewed 14 experts from 13 organizations located in Germany (Table 1). All experts were employed at these organizations; there were no freelancers involved in this study. We conducted the interviews via phone from October 2018 to January 2019. They lasted between 41 and $90 \mathrm{~min}$. All interviews

Table 1 Overview of Expert Interviews

\begin{tabular}{|c|c|c|c|c|}
\hline Expert & $\begin{array}{l}\text { Organization } \\
\text { Pseudonym }\end{array}$ & $\begin{array}{l}\text { Organization Description (Size } \\
\text { Category) }\end{array}$ & $\begin{array}{l}\text { Expert Position in } \\
\text { Organization }\end{array}$ & Duration \\
\hline 1 & ENERGYPLAT & $\begin{array}{l}\text { Digital platform provider for } \\
\text { energy management (B) }\end{array}$ & $\begin{array}{l}\text { Head of Product Man- } \\
\text { agement }\end{array}$ & $1: 30 \mathrm{~h}$ \\
\hline 2 & INSURANCE & Insurance company (E) & Project Manager & $1: 04 \mathrm{~h}$ \\
\hline 3 & CITYMOBIL & Utilities and public transport (C) & Project Manager & $1: 29 \mathrm{~h}$ \\
\hline 4 & GLOBALSYS & Global IT solution provider (E) & $\begin{array}{l}\text { IT Architect and } \\
\text { Consultant }\end{array}$ & $1: 17 \mathrm{~h}$ \\
\hline 5 & GLOBALSYS & Global IT solution provider (E) & Program Manager & $1: 27 \mathrm{~h}$ \\
\hline 6 & ENERGYTRADE & $\begin{array}{l}\text { Digital platform provider for } \\
\text { energy trading }(C)\end{array}$ & Project Manager & $1: 11 \mathrm{~h}$ \\
\hline 7 & ITSOLUTION & $\begin{array}{l}\text { IT solution provider, consulting, } \\
\text { software development (B) }\end{array}$ & Lead Architect & $1: 13 \mathrm{~h}$ \\
\hline 8 & ITCONSULT & IT consulting (D) & Program Manager & $0: 41 \mathrm{~h}$ \\
\hline 9 & DIGIBUSINESS & $\begin{array}{l}\text { IT and digital business solution } \\
\text { provider (D) }\end{array}$ & Project Steering & $1: 06 \mathrm{~h}$ \\
\hline 10 & UTILCONSULT & $\begin{array}{l}\text { Management consulting for } \\
\text { utilities (B) }\end{array}$ & $\begin{array}{l}\text { Team Lead for Digi- } \\
\text { talization \& IT }\end{array}$ & $1: 14 \mathrm{~h}$ \\
\hline 11 & PHARMACHINES & $\begin{array}{l}\text { Machinery construction for the } \\
\text { pharmaceutical industry }(\mathrm{C})\end{array}$ & $\begin{array}{l}\text { Product Manager for } \\
\text { Service/Support }\end{array}$ & $0: 48 \mathrm{~h}$ \\
\hline 12 & PACKMACHINES & $\begin{array}{l}\text { Plant construction for packing } \\
\text { food/non-food items (B) }\end{array}$ & $\begin{array}{l}\text { Head of After Sales } \\
\text { Service }\end{array}$ & $0: 41 \mathrm{~h}$ \\
\hline 13 & INTERNALIT & $\begin{array}{l}\text { Internal IT provider of a machin- } \\
\text { ery manufacturer (D) }\end{array}$ & $\begin{array}{l}\text { IT Solution Consul- } \\
\text { tant }\end{array}$ & $1: 00 \mathrm{~h}$ \\
\hline 14 & FIELDSERVICE & $\begin{array}{l}\text { Provider of field service manage- } \\
\text { ment software (A) }\end{array}$ & CEO & $1: 04 \mathrm{~h}$ \\
\hline
\end{tabular}


were audio-recorded and selected sections were transcribed for detailed analysis. We only provide organization pseudonyms and the expert's position in Table 1 as we guaranteed anonymity to all interviewees. As an indication of the company size, we provide their number of employees in the following five categories: A: <50; B: 51-250; C: 251 to 1000; D: 1001 to 10,000 ; E: $>10,000$.

During the interviews, we followed a semi-structured guideline that covered the following sections with several questions each:

1. Introduction of interviewer and expert, description of the expert's organization, expert's background, and his/her role in the organization.

2. Identification of smart service innovation processes that the expert was involved in and the selection of a specific SSSE project for closer analysis in the following sections of the interview.

3. Initiating state of the smart service innovation process, including the initiating actor and triggering impulse for starting the SSSE project.

4. Realizing state of the smart service innovation process, including organization of the SSSE project, involved internal and external actors, overall project management approach, work contributions, approaches, and method use of the different actors.

5. Outcoming state of smart service innovation process, including the resulting value proposition and resource configuration of the smart service system, potential market diffusion, and scale-up by the time of the interview.

With this interview guideline, we provided a general orientation for the interview but also left some flexibility for additional insights and thoughts of the experts. Our rationale was to stimulate the experts to provide rich information on the smart service innovation processes and corresponding SSSE projects, the involved actors, their work contributions to the projects, and relevant context. Following the S-D logic as described above, our interview guideline did not include predefined conceptualizations of roles but we asked open questions to ensure that we identify and characterize actors in terms of their "distinctly constituted identities" (Vargo and Lusch 2016, p. 7). With this interview guideline, we also strived for identifying the actors' roles with the perspective of "ecosystem-as-structure" (Adner 2017, p. 44) by putting our focus on the activities and work contributions that the different actors render for the development of the smart service system.

\subsection{Data Analysis}

During data analysis, we followed the steps of compiling, disassembling, reassembling, and interpreting according to Yin (2018). As for the first step, we organized the interview recordings and interview metadata in a cloud-based data storage that was accessible to all researchers. We listened to the recordings of the interviews multiple times and used a shared spreadsheet file with summary sheets for each interview. In these summary sheets, we captured our key insights along the sections of the interview guideline. We also added labels for the specific SSSE project that the expert selected and reported on as well as memos with our initial thoughts and insights from the interviewer's perspective. For each interview, one of the researchers 
of our author team (usually the interviewer) was assigned as the responsible analyst. For all interviews, a second researcher performed plausibility checks by also listening to the recordings and discussing his impressions with the responsible analyst at the different steps of data analysis as described in the following.

In the disassembling step, we broke down the interview data of each respondent into smaller fragments and specifically tried to identify the text passages in which the experts reported on the involvement of multiple actors in the SSSE project. We selectively transcribed the relevant fragments of interviews and used descriptive codes to label the actors that we were able to identify. Here, we coded actors on the level of organizations (and not human individuals) as all experts naturally reported on the SSSE project from the perspective of the firm they represent. In each project, we assigned an ID to specific actors that we were able to identify. When assigning the IDs, we took the perspective of the designated service provider in a project and distinguished between three types of actors: customers (both individuals and organizations; type C), provider organizations (type P), and external organizations (type E). To distinguish the different actors across all SSSE projects of our sample, we denoted them with $1 \ldots n$. For instance, in project 1 we identified actors $\mathrm{C} 1$, P1, as well as E1, E2, E3, E4, and E5 from our interview with the expert who was employed at organization E1. In this step, we further used descriptive codes to describe the specific activities, resources, and competencies (including knowledge and skills) that these actors (e.g., the competence for user interface design) brought into the SSSE projects. While coding, we tried to stick closely to the terminology as used by our informants (in the sense of open codes or in vivo codes; Yin 2018). We summarized our findings in detailed interview memos that gave descriptions of the overall service ecosystem as described by the experts including the actors that we were able to identify as well as an initial conceptualization of their role, which we derived from their activities, resources, and competencies. We also created graphical sketches to depict the service ecosystem structures.

As for the reassembling step, we compiled an overview of all actors and roles that we derived from the previous step and searched for similarities and differences. We constantly compared our interview memos and codes across the different SSSE projects as recommended by Yin (2018). Precisely, we revisited each interview and checked if roles from the other interviews were also present and by which actors they were enacted. We also examined if the assignment of roles to actors differed. Based on the iterative process of comparing and discussing, we jointly grouped similar competencies and resources into a consolidated set of roles that we applied across all interviews. During this process, we added new roles when we identified competencies and resources that we had not covered before. We also rearranged, merged, and split up roles when considered necessary. In the end, we updated the graphical sketches and interview memos so that they corresponded with the final, consolidated set of roles.

In the interpreting step, we then went on with further condensing our findings and searching for possible explanations of the different constellations of actors and roles in the various service innovation processes. Here, we first systematized the set of roles into different groups of roles (Primary and Secondary Roles; Engineering and Operations subsystems) which were, amongst others, inspired by the corresponding 
actors' degree of involvement (Ekman et al. 2016; Jonas and Roth 2017) and different states of the innovation process (Edvardsson et al. 2018). Second, we also were able to derive different smart service innovation patterns based on similar actor-role constellations in SSSE projects (also reflecting different institutional arrangements in service ecosystems; Vargo and Lusch 2016).

\section{Results}

\subsection{Identified SSSE Projects}

The experts in our sample reported on a broad range of service innovation processes and corresponding SSSE projects. The value propositions to be developed comprised, for instance, mobility and charging services for electric vehicles, remote support for industrial equipment, car delivery tracking, and energy management (Table 2). The target customers of the new value propositions were anonymous consumer markets (e.g., public transport passengers in project 10), rather well-defined customer segments (e.g., users of electric vehicles in project 3) or even specific individual actors (e.g., project 8 with a customer-specific development of a car delivery tracking service by ITCONSULT). Depending on whether the value proposition was targeted at consumers or businesses, we marked the value proposition as either business-tobusiness (B2B) or business-to-consumer (B2C) in Table 2.

All SSSE projects in our sample utilize data from the IoT as part of the designated value creation. However, smart products have different functions in the resulting smart service systems. First, in most of the B2B projects, the smart product is in the focus and digital services are built around it (e.g., in projects 4, 9, 11-14). These projects mainly support the digital servitization of manufacturers (Sklyar et al. 2019 b), in which the value propositions move from a focus on tangible goods towards integrated solutions and service offerings (e.g., through a pay-per-use business model for industrial equipment and machinery). Second, smart products provide access to high-quality real-world data. This data is combined with other data to enable or at least improve the value creation efficiency of service systems. Examples include smart parking (project 5), energy distribution network control (project 1), and selfservice charging for electric vehicles (project 3). Third, smart products are used by actors to optimize their business processes and collaboration with other actors (projects 3,8). The different approaches to utilizing smart products as key resources in smart service systems can also be pursued in combination. This is especially visible from those cases where actors are both providers and users of their service offerings, e.g., when charging the cars of the firm's fleet (project 3) or the firm's service department uses a remote support service to reduce on-site visits for servicing industrial doors (project 9).

\subsection{Roles of Actors in SSSE Projects}

Our analysis of the 14 SSSE projects led to the conceptualization of 17 roles in total. Tables 3 and 4 provide an overview of all roles that we identified from our 
Table 2 Overview of SSSE Projects

\begin{tabular}{|c|c|c|}
\hline No & $\begin{array}{l}\text { Value Proposition } \\
\text { (Type) }\end{array}$ & Project Description \\
\hline 1 & $\begin{array}{l}\text { Energy distribution } \\
\text { network control } \\
\text { (B2B) }\end{array}$ & $\begin{array}{l}\text { Development of a digital service that stabilizes the energy distribution } \\
\text { grid by predicting instabilities and incentivizing individual households } \\
\text { to change their energy consumption behavior }\end{array}$ \\
\hline 2 & $\begin{array}{l}\text { Diabetes prevention } \\
\text { app (B2C) }\end{array}$ & $\begin{array}{l}\text { Customization of an app that uses blood sugar measurements, activity } \\
\text { tracking, and reporting for people to influence their behavior. The app } \\
\text { is a 3rd party white-label solution offered by INSURANCE }\end{array}$ \\
\hline 3 & $\begin{array}{l}\text { Electric vehicle } \\
\text { charging (B2C) }\end{array}$ & $\begin{array}{l}\text { Development of a billing and access service to allow for a simple and } \\
\text { cost-efficient charging of e-vehicles in the city of CITYMOBIL }\end{array}$ \\
\hline 4 & $\begin{array}{l}\text { Fleet and mainte- } \\
\text { nance management } \\
\text { (B2B) }\end{array}$ & $\begin{array}{l}\text { Development of a system by GLOBALSYS for a manufacturer of } \\
\text { commercial vans. It enables the sharing of data between the manufac- } \\
\text { turer and customers for fleet management and maintenance planning }\end{array}$ \\
\hline 5 & $\begin{array}{l}\text { Smart parking } \\
\text { service }(\mathrm{B} 2 \mathrm{C})\end{array}$ & $\begin{array}{l}\text { Development of a service by GLOBALSYS for a large German city } \\
\text { that combines multiple data sources to identify areas with a high prob- } \\
\text { ability of free parking space. The service also allows reservations of } \\
\text { parking spaces }\end{array}$ \\
\hline 6 & $\begin{array}{l}\text { Energy trading } \\
\text { platform }(\mathrm{B} 2 \mathrm{~B})\end{array}$ & $\begin{array}{l}\text { Development of a tendering service as an alternative to expensive } \\
\text { energy exchanges to improve the trader's margin. It supports placing } \\
\text { tenders in the marketplace, shows current tenders and market pricing }\end{array}$ \\
\hline 7 & $\begin{array}{l}\text { Customer service } \\
\text { for public transport } \\
\text { (B2C) }\end{array}$ & $\begin{array}{l}\text { Development of a platform by ITSOLUTION for a municipal public } \\
\text { transport organization, including services for end-users, e.g., master } \\
\text { data management, ticket purchasing, subscriptions, etc }\end{array}$ \\
\hline 8 & $\begin{array}{l}\text { Car delivery track- } \\
\text { ing }(\mathrm{B} 2 \mathrm{~B})\end{array}$ & $\begin{array}{l}\text { Customer-individual development of a digital monitoring service } \\
\text { by ITCONSULT for a car manufacturer that allows for the real-time } \\
\text { tracking of car delivery }\end{array}$ \\
\hline 9 & $\begin{array}{l}\text { Industrial doors } \\
\text { remote support } \\
(\mathrm{B} 2 \mathrm{~B})\end{array}$ & $\begin{array}{l}\text { Development of a remote support service for industrial doors by DI- } \\
\text { GIBUSINESS for the door manufacturer }\end{array}$ \\
\hline 10 & $\begin{array}{l}\text { Intermodal public } \\
\text { transport service } \\
\text { (B2C) }\end{array}$ & $\begin{array}{l}\text { Development of a digital service (incl. app and information terminals) } \\
\text { for citizens that provides alternatives based on location and destina- } \\
\text { tion with the integration of multiple modes of transport }\end{array}$ \\
\hline 11 & $\begin{array}{l}\text { Virtual reality- } \\
\text { based user training } \\
\text { service }(\mathrm{B} 2 \mathrm{~B})\end{array}$ & $\begin{array}{l}\text { Development of a virtual reality training service using maintenance } \\
\text { simulations of PHARMACHINES' products, which one of its cus- } \\
\text { tomers triggered }\end{array}$ \\
\hline 12 & $\begin{array}{l}\text { Video chat remote } \\
\text { support }(\mathrm{B} 2 \mathrm{~B})\end{array}$ & $\begin{array}{l}\text { Development of a video-chat-based remote support app to support } \\
\text { customers in resolving incidents with PACKMACHINES' products }\end{array}$ \\
\hline 13 & $\begin{array}{l}\text { Predictive mainte- } \\
\text { nance }(\mathrm{B} 2 \mathrm{~B})\end{array}$ & $\begin{array}{l}\text { Development of a showcase of an availability-based business model as } \\
\text { part of a governmentally funded consortium project }\end{array}$ \\
\hline 14 & $\begin{array}{l}\text { Digital customer } \\
\text { portal }(\mathrm{B} 2 \mathrm{~B})\end{array}$ & $\begin{array}{l}\text { Development and customization of software that FIELDSERVICE's } \\
\text { customer in facility management can use to provide its customers with } \\
\text { a customer portal (instead of paper-based documentation) }\end{array}$ \\
\hline
\end{tabular}

interview data. The column Projects indicates in which projects the respective role was identified as being actively involved in the SSSE project.

We clustered the set of roles into Primary and Secondary Roles (Fig. 1). Primary Roles identify contributions that are usually required due to the characteristics of smart service systems. They were mentioned by almost all interviewees as being involved in the SSSE projects with few exceptions. Secondary Roles relate to more specialized contributions for which the demand is identified during a project. There- 
Table 3 Identified Primary Roles in SSSE projects

\begin{tabular}{llll}
\hline $\begin{array}{l}\text { Role } \\
\text { Name }\end{array}$ & Key & Activities in the Service Ecosystem & Projects \\
\hline $\begin{array}{l}\text { Project } \\
\text { Sponsor }\end{array}$ & PS & $\begin{array}{l}\text { Initiates, sponsors, and often manages the overall project } \\
\text { Operates and offers the service towards the Service Beneficiary } \\
\text { after completion of the SSSE project }\end{array}$ & $1-14$ \\
$\begin{array}{l}\text { Digital } \\
\text { Innovator }\end{array}$ & DI & $\begin{array}{l}\text { Provides methodological support for the innovation process } \\
\text { Facilitates the creation of service ideas }\end{array}$ & $1-14$ \\
$\begin{array}{l}\text { Designs business model } \\
\text { Integrator }\end{array}$ & SI & $\begin{array}{l}\text { Develops technical concept, e.g., system architecture } \\
\text { Develops front-end, e.g., apps, and backend services, e.g., cloud } \\
\text { analytics and other software components }\end{array}$ & $1-14$ \\
Integrates existing systems, services, and devices \\
$\begin{array}{l}\text { Service } \\
\text { Operator }\end{array}$
\end{tabular}

fore, they were not always present, as can be derived from our interview data. For example, not all smart service systems were built using a cloud platform, so the role Cloud Platform Provider was not always required. Moreover, although irritating at first sight, it is not uncommon that SSSE projects were completed without involving actors with the role of a Customer Representative.

We further systematized the roles concerning their relation to different states of the service innovation process and, hence, to different subsystems of the overall service ecosystem at different points in time. The Engineering subsystem refers to contributions that are needed during the SSSE project for the development and implementation of the smart service system (i.e., the realizing state of service innovation). The Operations subsystem begins with the launch of the smart service offering into the market and refers to the actual value co-creation with the intended target group (i.e., the service customers in the outcoming state of service innovation). This systematization helped us to depict the contributions of actors with multiple roles in both the Engineering and Operations subsystems (e.g., actors who held the Service Operator role in both systems or actors who moved from the Customer Representative role during Engineering to a Service Customer role in Operations). In this study, our focus is on the Engineering subsystem and so is the focus of the presented set of roles. Nevertheless, we found that several roles continue to be relevant during Operations, and, hence, they are placed at the intersection of both subsystems (Fig. 1). However, we can certainly expect that there are more roles relevant to the Operations subsystem (and which could be added to the right-hand side of the set diagram), some of which we did not even learn about in our investigation of the Engineering subsystem.

\subsubsection{Primary Roles}

The four Primary Roles that we identified as being relevant to all SSSE projects are the Project Sponsor, Digital Innovator, System Integrator, and System Operator. The 
Table 4 Identified Secondary Roles in SSSE Projects

\begin{tabular}{|c|c|c|c|}
\hline Role Name & Key & Activities in the Service Ecosystem & Projects \\
\hline $\begin{array}{l}\text { Customer } \\
\text { Representative }\end{array}$ & $\overline{\mathrm{CR}}$ & $\begin{array}{l}\text { Informs the project as a target customer of the value } \\
\text { proposition } \\
\text { May be involved at various stages of the project, e.g., to } \\
\text { provide feedback during development }\end{array}$ & $\begin{array}{l}1,3-9,11 \\
13,14\end{array}$ \\
\hline $\begin{array}{l}\text { Market Research } \\
\text { Provider }\end{array}$ & MRP & $\begin{array}{l}\text { Provides customer insights, e.g. through a collection of } \\
\text { feedback on prototypes or service concepts }\end{array}$ & 2,5 \\
\hline $\begin{array}{l}\text { UI/UX } \\
\text { Specialist }\end{array}$ & UIS & $\begin{array}{l}\text { Designs customer journey and user interactions } \\
\text { Designs wireframes and mockups } \\
\text { Supports implementation of frontends }\end{array}$ & $\begin{array}{l}1,2,4,6,7 \\
13\end{array}$ \\
\hline $\begin{array}{l}\text { Data Analytics } \\
\text { Specialist }\end{array}$ & DAS & $\begin{array}{l}\text { Designs and implements big data solutions } \\
\text { Expert for data analysis, machine learning, etc }\end{array}$ & 8,13 \\
\hline Legal Advisor & LEG & $\begin{array}{l}\text { Provides advice regarding legal aspects of services and } \\
\text { contractual relationships between actors }\end{array}$ & 6 \\
\hline Regulator & REG & $\begin{array}{l}\text { Evaluates and approves service concepts regarding their } \\
\text { compliance with regulatory requirements }\end{array}$ & 1 \\
\hline $\begin{array}{l}\text { Original Equip- } \\
\text { ment Manufac- } \\
\text { turer }\end{array}$ & OEM & $\begin{array}{l}\text { Designs and produces physical products and equipment } \\
\text { that are part of the service system }\end{array}$ & $1,3,4,8-13$ \\
\hline $\begin{array}{l}\text { Hardware Sup- } \\
\text { plier }\end{array}$ & HWS & $\begin{array}{l}\text { Supplies sensors, communication modules, and other } \\
\text { hardware components }\end{array}$ & $4,5,9$ \\
\hline $\begin{array}{l}\text { Connectivity } \\
\text { Provider }\end{array}$ & $\mathrm{COP}$ & $\begin{array}{l}\text { Provides services for connecting smart products in the } \\
\text { field, e.g., cellular networks }\end{array}$ & $5,8,9,12$ \\
\hline $\begin{array}{l}\text { Cloud Platform } \\
\text { Provider }\end{array}$ & CPP & $\begin{array}{l}\text { Provides application-independent functionality in the } \\
\text { cloud, i.e. in a Platform-as-a-service Model (PaaS) } \\
\text { often with focus on IoT }\end{array}$ & $\begin{array}{l}1,2,5,6,9 \\
13,14\end{array}$ \\
\hline $\begin{array}{l}\text { Data Center } \\
\text { Operator }\end{array}$ & DCO & $\begin{array}{l}\text { Provides and operates IT-infrastructure, e.g. computa- } \\
\text { tion, storage, and network transfer }\end{array}$ & $1-4,12$ \\
\hline $\begin{array}{l}\text { Application } \\
\text { Software } \\
\text { Provider }\end{array}$ & ASP & $\begin{array}{l}\text { Develops and/or runs existing application software } \\
\text { systems that must be integrated }\end{array}$ & $2-7,10,14$ \\
\hline $\begin{array}{l}\text { Information } \\
\text { Service Provider }\end{array}$ & ISP & $\begin{array}{l}\text { Provides information for data-driven value creation, } \\
\text { e.g., weather forecasts, energy prices }\end{array}$ & 1 \\
\hline
\end{tabular}

Primary Roles contribute competencies and resources that address the core characteristics of smart service systems, namely enabling innovative value propositions using digital technologies. The actor assuming the Project Sponsor role is usually the initiator of the SSSE project who intends to develop a new value proposition. Usually, it is also the same actor that intends to successfully market this value proposition afterward in the role of the Service Provider (which is present in Operations). The Digital Innovator role is only present in the Engineering subsystem and responsible for developing new ideas into value propositions and business models utilizing the capabilities of digital technologies. The System Integrator role oversees the design and implementation of technical resources of the service system during Engineering, for which the Service Operator becomes responsible to run and maintain during Operations. We did not identify a Service Operator role in three of the 14 projects. We assume that was the case if projects were still in the earlier stages of 


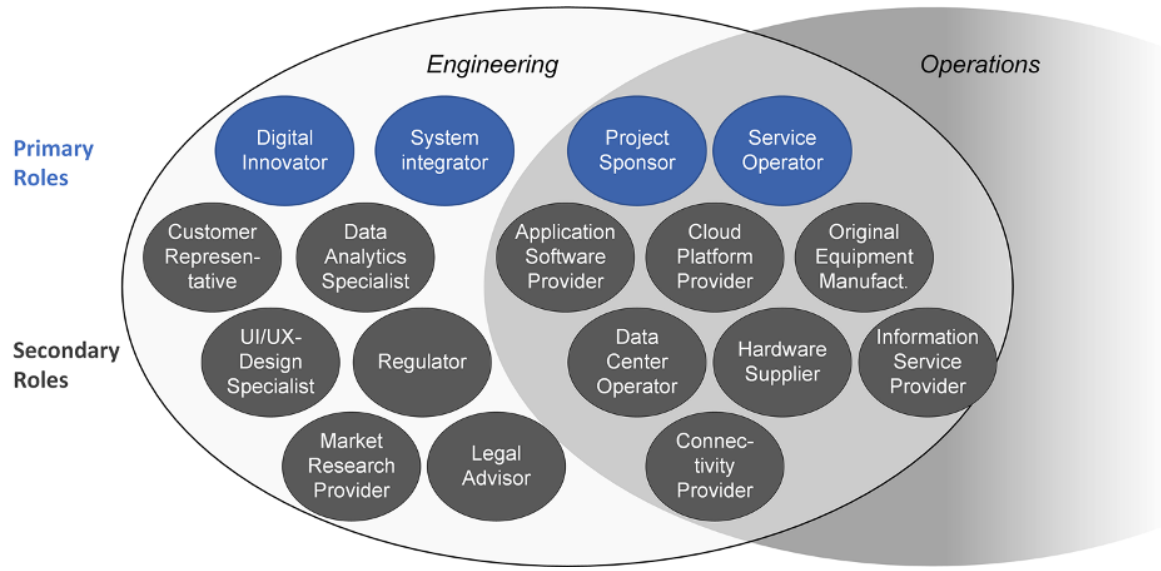

Fig. 1 Proposed Set of Roles in SSSE Projects

Engineering. Another reason might be that interviewees are typically only aware of a subset of activities and actors. So even if there were actors with a Service Operator role present in a project, the interviewee might not have reported on it. Thus, we still consider it as a Primary Role as the technical components of the smart service system need to be operated and maintained to enable the intended value proposition. Table 3 shows all Primary Roles along with the projects in which the corresponding activities were identified.

\subsubsection{Secondary Roles}

The 13 Secondary Roles can also be subdivided into roles that are exclusively relevant to the Engineering subsystem and some that span both the Engineering and Operations subsystems. The former comprises six roles including the Customer Representative, Market Research Provider, UI/UX-Design Specialist, Data Analytics Specialist, Legal Advisor, and Regulator.

The Customer Representative role represents the target user (usually referred to as the customer by the interviewees) of the new value proposition. We found a varying degree of involving this role. For example, INTERNALIT (project 13) invited potential customers to take part in focus group discussions early on. In project 7 , users of the public transport service were represented through a passenger advisory board. In contrast, the electric vehicle charging service (project 3) was first designed and implemented without end-user involvement. Only in later project stages, paid testers were asked for feedback. Projects 10 and 12 even did not involve the Customer Representative role at all. In project 10, the transport service was developed without the involvement of (potential) future users. However, after it turned out to have low market acceptance, the provider tried to get in contact with passengers to gather insights for improvements. In project 12, PACKMACHINES developed the video-chat service together with a software development firm without involving their customers. They started gathering feedback first when they presented the ini- 
tial version of the smart service system in sales appointments. Generally, in projects where the SSSE project is initiated by a manufacturer in a B2B setting (holding the Project Sponsor role), customer involvement appeared to be less intensive or nonexisting during the project. The interview data suggest that the manufactures (e.g., PACKMACHINES in project 12) preferred to have a working prototype before they involve customers.

An actor with the Market Research Provider role offers services to gain customer insights, which help to shape the characteristics of the intended value proposition of the smart service system. For the smart parking solution developed in project 5 , a tool called "prediction markets" was used to collect opinions (votes) on features and pricing of the service from a large set of users. Another example is the diabetes prevention app in project 2 , which was tested with many potential users by an external test provider to gain feedback on the usability of an app prototype. $U X / U I$ Design Specialists take care of user experience (UX) and user interfaces (UI). They support a user-centered approach to the design of technical systems. Consequently, they focus on interaction design and touchpoint management (e.g., through modeling customer journeys). The Data Analytics Specialist role denotes a set of competencies related to storing, processing, and analyzing large amounts of data. For example, in project 8 , a specialist company was hired by the Project Sponsor to take on this role. Legal Advisors provide help with designing contracts, privacy statements, and other legal issues regarding the planned service. In project 6 , a law office was involved to elaborate on the terms and conditions as well as a privacy statement for the designated energy trading platform. Regulators are responsible for the approval of service concepts that operate in regulated markets, e.g., energy, banking, or medical services. For example, in project 1, the planned service for energy distribution network control needed the approval of the German Federal Network Agency.

The other seven Secondary Roles are relevant to both Engineering and Operations. These are the Original Equipment Manufacturer (OEM), Hardware Supplier, Connectivity Provider, Cloud Platform Provider, Data Center Operator, Application Software Provider, and Information Service Provider. The OEM manufactures physical goods, equipment, and machinery, which usually need to be connected to the Internet to become part of the smart service system. Examples of OEM products in our sample include energy equipment for private homes (project 1), charging points for electric vehicles (project 3), commercial vehicles (project 4), and industrial doors (project 9). Hardware Suppliers offer various devices, such as communication modules or sensors to retrofit existing OEM products or physical facilities and environments (i.e., the servicescape) with computational capacity, sensors, communication capabilities, and other computing equipment. Thereby, OEM products are transformed into smart products and servicescapes into smart environments. For example, in project 5, parking sensors were installed to detect available on-street parking spots. Connectivity Providers typically are telecommunication operators who offer data transmission services such as mobile data plans. These are used to communicate with smart products once they are deployed. Cloud Platform Providers offer an infrastructure to operate software components. Some of them might include higher-level services for IoT-applications, e.g., device management or analysis of data streams. Data Center Operators provide and manage technical 
computing infrastructure, including computation, storage, and networking, which are needed as runtime environments for platforms, services, or software components (projects 1, 3, 4). Application Software Providers offer individual or standardized software products, which are typically integrated into the smart service system. Examples include a fleet management application (project 4) as well as applications for public transport information and ticketing (project 7, 10). The Information Service Provider delivers data that can become part of the data value chain in a smart service system. This role was needed in project 1 for ensuring access to information on energy prices. Table 4 shows the list of Secondary Roles along with the project in which the respective activities were found.

\subsection{Ecosystem Dynamics in Service Innovation}

As indicated by the previous distinction between Engineering and Operations subsystems, the interview data also allowed us to describe some of the dynamics of roles and their assignment to actors during service innovation processes. As we cannot illustrate the dynamics of all SSSE projects in this article, we provide the example of project 4 (Fig. 2). Actor P4 planned to provide fleet management and maintenance services around its commercial vans. At the initiating state of the service innovation process, $\mathrm{P} 4$ identified various competencies required to realize this concept, e.g., those of a Digital Innovator, a System Integrator, and a UI/UX Design Specialist. For the transition into the realizing state, these required roles had to be filled with actors. Altogether, these actors and P4 were supposed to form the Engineering subsystem that collaboratively works on the design and implementation of the new service idea. Two external System Integrators (E12, E13) were chosen and a design agency (E14) was hired for the UI/UX design. The fleet management

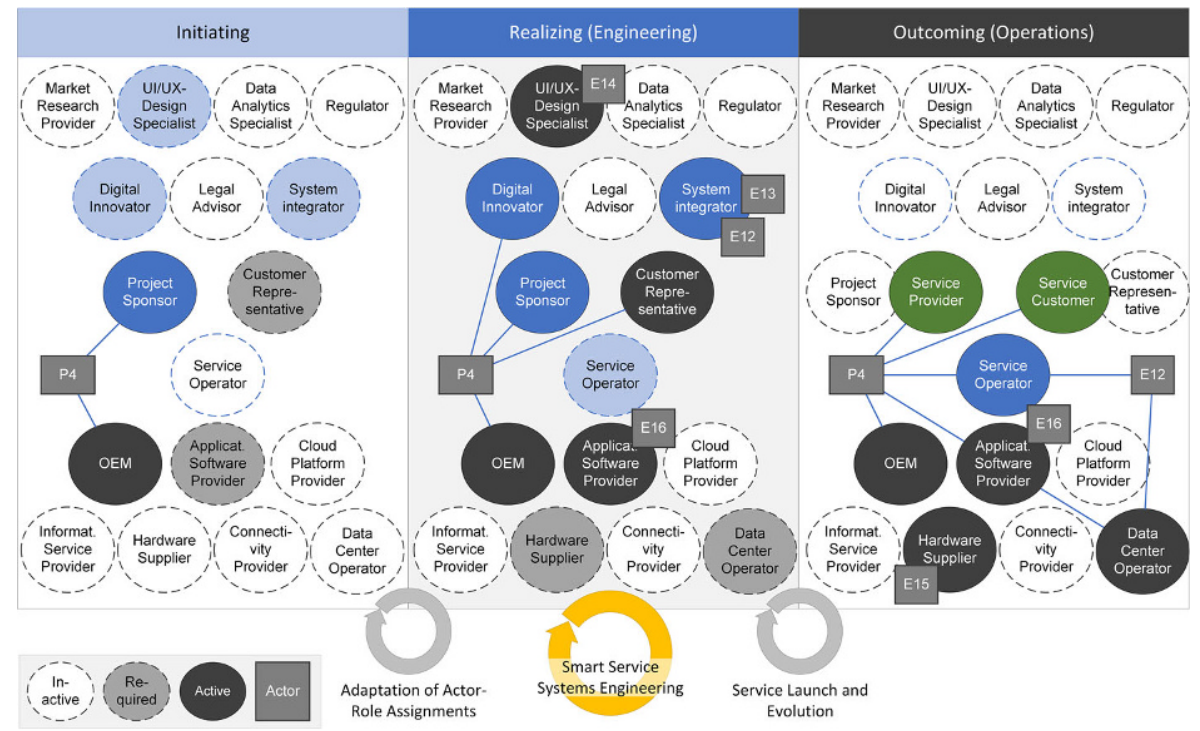

Fig. 2 States of Service Innovation in a Service Ecosystem 
functionality was delivered by an external Application Service Provider (E16). They also worked together with P4 on interfaces for the integration of fleet management functionality. As the actor P4 itself intended to use the service for its internal maintenance operations, it also assumed the role of the Customer Representative. External target customers were fleet managers, but their involvement in this phase is unknown, which is why we do not include them here as additional Customer Representatives. Due to its innovation capabilities and domain expertise, the actor P4 also took over the Digital Innovator role and developed the value proposition and business model. During the SSSE project, the actors also determined additional competencies required for Operations, e.g. a Service Operator, and a Data Center Operator. The initial launch of the service offering marks the transition to the outcoming state of the service innovation process. For that, the required roles had to be filled with actors that take on the roles of the Data Center Provider and Service Operator. In this case, parts of the systems were operated and managed by actor P4 itself and other parts by E12. Therefore, these two actors shared the roles of Service Operator and Data Center Operator. In the outcoming state, some of the roles from the realizing state became inactive again as their project work was finished. In this state, two additional roles of Service Provider and Service Customer become active. However, as our study focusses on the Engineering subsystem, they are out of scope and only mentioned for consistency here.

\subsection{Actor-Role Assignments in the SSSE Projects}

Our comparison between the different interviews showed that some actors accumulated quite a few roles in SSSE projects whereas the same roles were spread across many actors in other projects. Hence, specific actors can assume one or more roles. Equally, there were SSSE projects, where multiple actors were assigned to the same role. Furthermore, we found that not all 17 roles were present in all 14 projects. There are even some roles that were present in a single SSSE project only. Considering the distribution of roles across actors, we saw that all projects required multiple competencies and resources from different organizations.

To illustrate the assignments of roles to actors, we distinguished between three types of actors: customers (C), provider organizations (P), and external organizations (E). Table 5 shows which roles were assigned to which actor in each project. Each column describes the assignment of actors to roles in the project indicated by the project number in the top row. An asterisk $(*)$ indicates the co-existence of multiple, similar actors, which were not further differentiated by the experts. For example, in project 7, several actors provided applications for ticketing, billing, and travel information to be integrated. A minus sign (-) indicates that no actor was actively holding that specific role in the respective project. The last row displays the total number of identified actors in each project. The actors in bold indicate the firms where our experts that we interviewed were employed at. About half of the interviewed experts belonged to actors that we considered as external organizations (i.e., in projects $1,4,5,7-9,13-14$ ).

It is visible that most provider organizations had to rely on external organizations for taking on roles that can be broadly summarized under software development and 


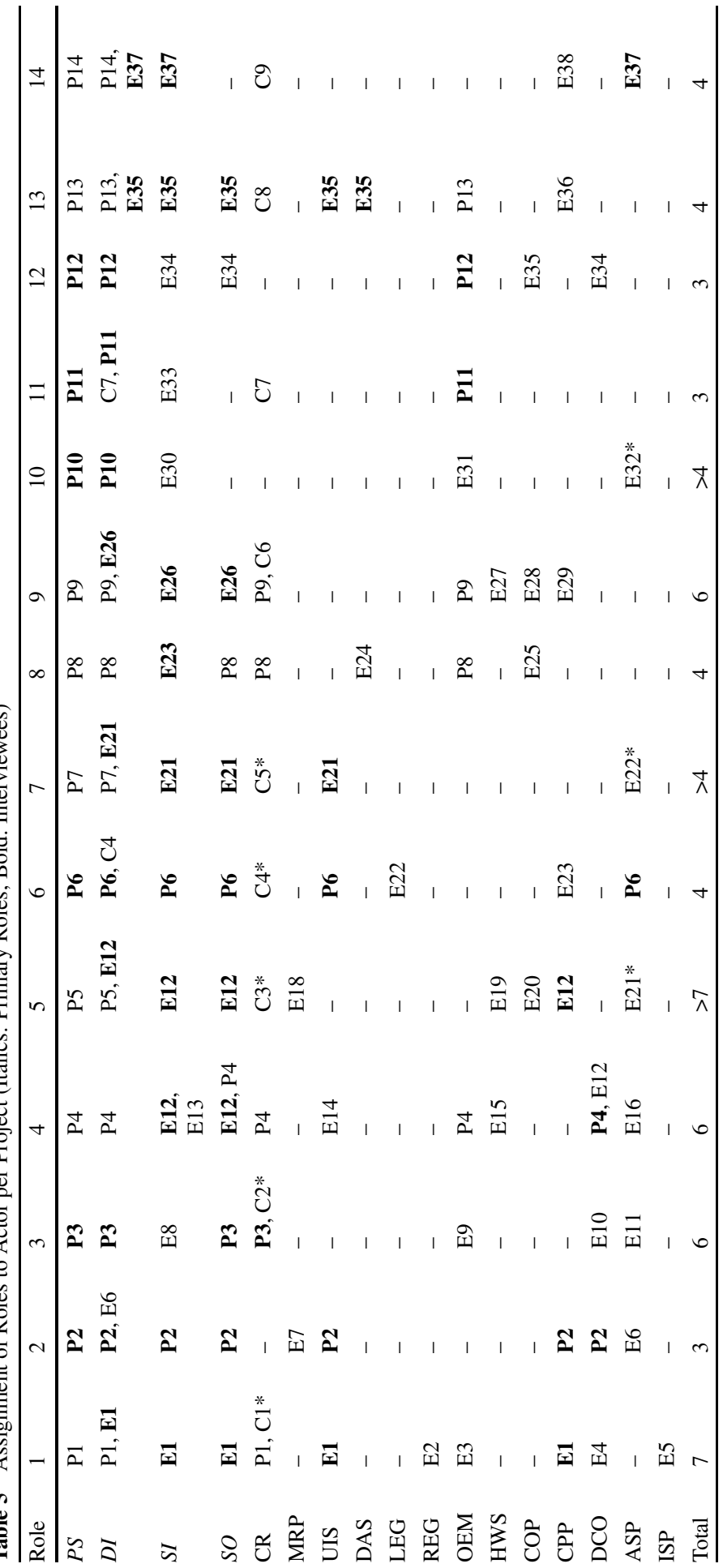


system integration (projects 1, 3-5, 7-12). The UI/UX Design Specialist role was enacted in six projects, which indicates an awareness of the importance of smart service systems usability. The required skills were either found at the provider organization (projects 2, 6, 13) or acquired from external actors (projects 1, 4, 13). The Digital Innovator role is often (projects 1, 2, 5-7, 9, 13, 14) shared between the provider organization and external organizations. Interestingly, there is not a single project where the Digital Innovator role was held by an actor with no other roles. Instead, it was an additional role of actors who also assume the Project Sponsor, the System Integrator, the Application Software Provider, or even the Customer Representative role. In project 13, for instance, INTERNALIT and further consortium partners held the role of the Digital Innovator together and organized focus group discussions with customers.

External actors with the role of the Market Research Provider were involved when value propositions were targeted at large anonymous customer groups to get insights about demands and feedback on prototypes (projects 2, 5). For example, a "prediction market" was used to collect opinions on features and pricing from potential users of the smart parking service (project 5). Customers were involved by taking the role of the Customer Representative in all projects except 10 and 12 . In project 11, the customer actor even assumed the role of the Digital Innovator as it provided the idea for the virtual reality training service to the provider organization PHARMACHINES. Our findings further illustrate that not only the customer but also the provider organization can take over the Customer Representative role in an SSSE project (projects 3, 4, 8, 9). This occurred when a service was intended to be used by the provider organization itself.

The Secondary Roles were frequently assumed by actors that were external to the actor with the Project Sponsor role. Hence, these roles represent competencies and resources that were often not available at the provider organization. Actors with Secondary Roles were integrated closely into the collaborative project work particularly if their work contributions had to be individualized for the respective project. However, these roles were often also taken by actors that had a Primary Role if they possessed the required competencies and resources. Other Secondary Roles refer to the provision of technical components of a smart service system. These contributions often comprise mature, well-defined products and services, for which effortful adaptations are neither possible nor required. Therefore, actors assuming these roles do not require active participation in the project work. Usually, the integration of these work contributions takes place by buying the products or services through standard market-based transactions.

\subsection{Smart Service Innovation Patterns}

From our analysis of the actor-role assignments and a reflection of the underlying dynamics during the service innovation processes, we identified four typical constellations, which we call smart service innovation patterns. These patterns indicate a certain strategic setup of an SSSE project. To distinguish these patterns, we looked at the assignments of roles to actors, which indicate their contributions of resources and competencies to the service ecosystem. We describe the patterns 


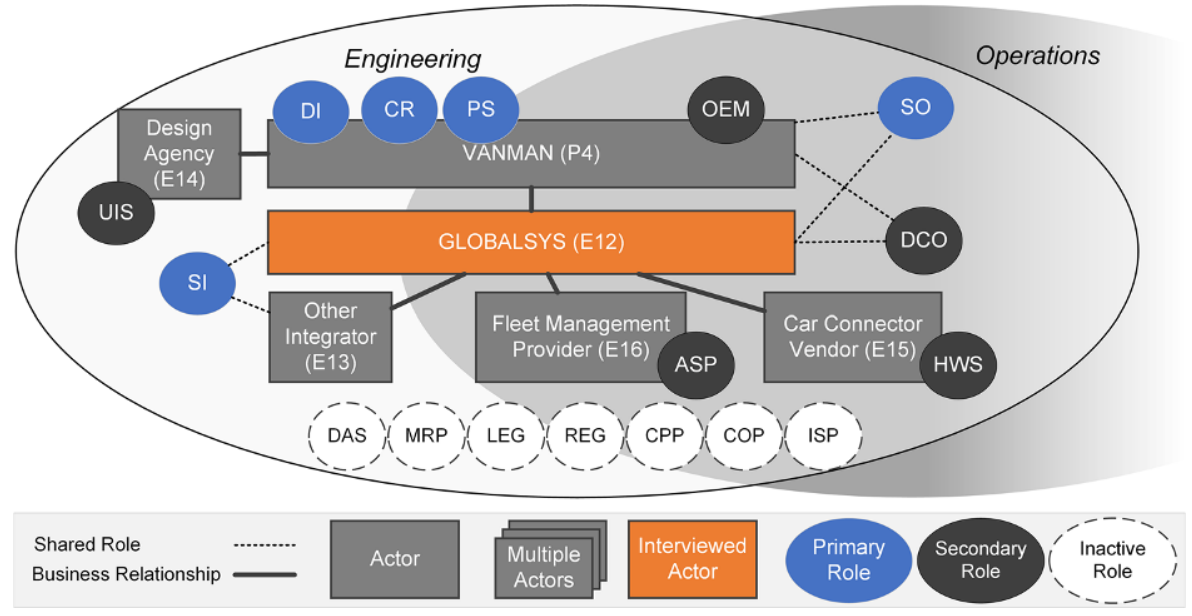

Fig. 3 Example of the Provider-driven Development Pattern (Project 4)

using our proposed set of roles and the defined actor types customer organization, provider organization, and external organizations. As IT-related competencies are split up into several roles, we simply use the term IT provider organization to denote actors with one or more of the following roles: System Integrator, Cloud Platform Provider, and Application Service Provider. Additionally, we provide a graphical model of an example service ecosystem for each pattern. These models show the involved actors as boxes, which are identified by their identifier as used in Table 5. Each actor has one or more roles assigned to it. They are represented using the short names of roles in small circles overlapping the actors. Any role that is not used in an ecosystem is displayed as inactive (in white with a dotted border). This indicates

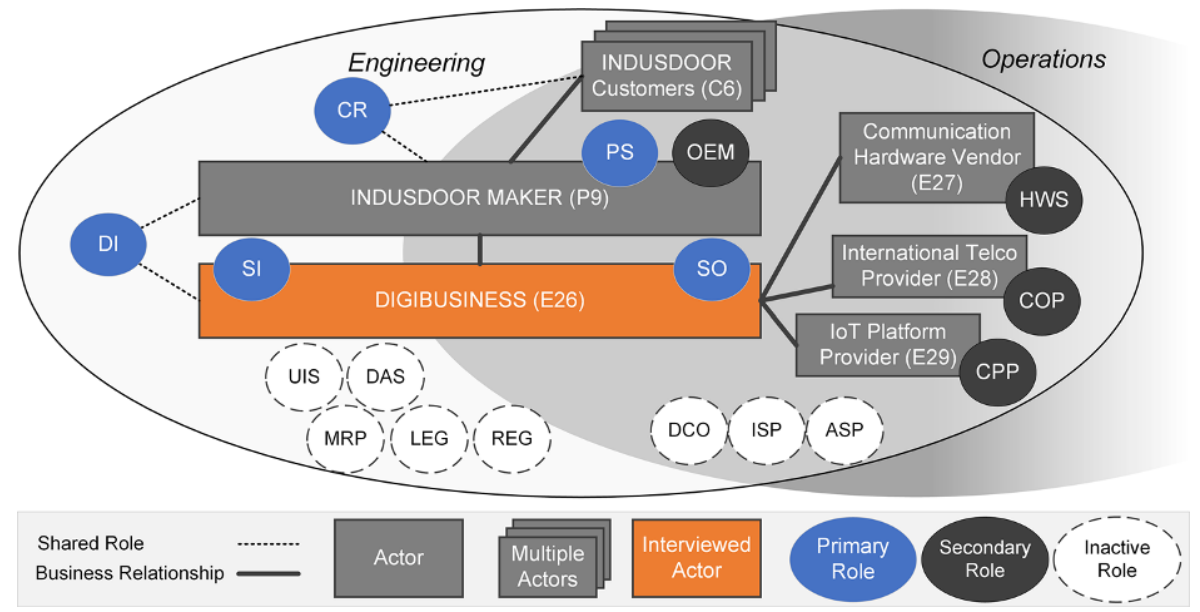

Fig. 4 Example of the Joint Development Pattern (Project 9) 


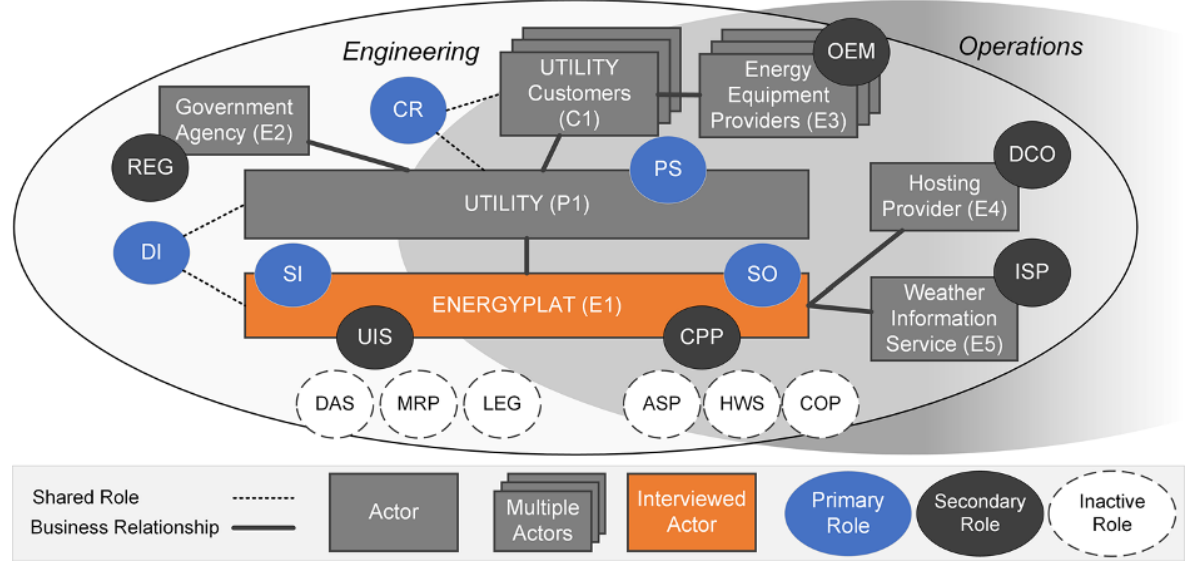

Fig. 5 Example of the White Label Solution Pattern (Project 1)

that the respective competency was not identified in this ecosystem, and hence, no actor was enacting this role.

The four patterns comprise Provider-driven Development, Joint Development, White Label Solution, and Forward Integration. In the Provider-driven Development pattern, a provider organization holds the Digital Innovator role. This actor initiates the creation of new value propositions. Another actor with the Customer Representative role may additionally assume the Digital Innovator role and contribute to the innovation process, e.g., through industry insights, requirements definition, and feedback. In this pattern, the IT provider organizations are only responsible for the technical implementation of the new service concept. Further external actors might be contracted to build and operate technical parts of the smart service system. Examples for this pattern include the electric vehicle charging service (project 3) and the fleet management for commercial vans (project 4; depicted in Fig. 3). In the constellation described by this pattern, the provider organization as the driving actor needs to have strong innovation and project management competencies to create

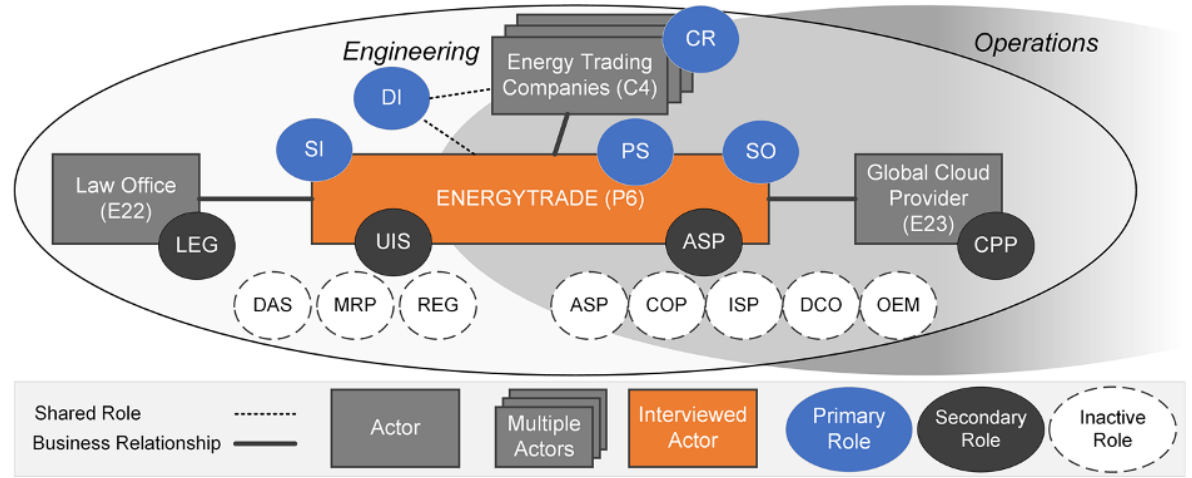

Fig. 6 Example of the Forward Integration Pattern (Project 6) 
both the service concept and manage the actors required for the implementation and/or operation of the smart service system.

In the Joint Development pattern, a provider organization works together with an external IT provider organization that usually holds the System Integrator role. Both actors share the Digital Innovator role. Hence, this setup requires digital innovation competencies at both actors. One example of this innovation pattern is project 7 , which dealt with an integrated service for public transport information, ticketing, and subscriptions. Another example is project 13 in which an IT-subsidiary of a machinery manufacturer developed a predictive maintenance service. Finally, in

Table 6 Smart Service Innovation Patterns

\begin{tabular}{|c|c|c|}
\hline Name & Characteristics & Projects \\
\hline \multirow{5}{*}{$\begin{array}{l}\text { Provider- } \\
\text { driven } \\
\text { Devel- } \\
\text { opment }\end{array}$} & $\begin{array}{l}\text { Service innovation takes mainly place at the provider organization with the } \\
\text { designated Service Provider role, possibly in collaboration with (future) cus- } \\
\text { tomers }\end{array}$ & $\begin{array}{l}3,4,8 \\
10-12\end{array}$ \\
\hline & $\begin{array}{l}\text { IT-related competencies are typically not available internally, corresponding } \\
\text { roles are not taken on by the provider organization }\end{array}$ & \\
\hline & $\begin{array}{l}\text { Strong innovation and project management capabilities are required at the } \\
\text { provider organization }\end{array}$ & \\
\hline & $\begin{array}{l}\text { High dependency on external know-how, especially from IT provider orga- } \\
\text { nizations with the System Integrator role, who are only responsible for the } \\
\text { technical implementation }\end{array}$ & \\
\hline & Entrepreneurial risk at the provider organization & \\
\hline \multirow{4}{*}{$\begin{array}{l}\text { Joint } \\
\text { Devel- } \\
\text { opment }\end{array}$} & $\begin{array}{l}\text { Service innovation is driven by the provider organization together with an } \\
\text { external actor with the System Integrator role }\end{array}$ & $7,9,13$ \\
\hline & Both actors assume the Digital Innovator role together & \\
\hline & $\begin{array}{l}\text { Lower requirements for innovation and project management capabilities at the } \\
\text { provider organization due to external support }\end{array}$ & \\
\hline & Entrepreneurial risk at the provider organization & \\
\hline \multirow{6}{*}{$\begin{array}{l}\text { White } \\
\text { Label } \\
\text { Solu- } \\
\text { tion }\end{array}$} & $\begin{array}{l}\text { An actor with strong IT capabilities (i.e., an IT provider organization) devel- } \\
\text { ops, builds, and runs an innovative value proposition on its own }\end{array}$ & $\begin{array}{l}1,2,5 \\
14\end{array}$ \\
\hline & $\begin{array}{l}\text { The IT provider organization offers a white label solution for a common prob- } \\
\text { lem to (multiple) provider organizations }\end{array}$ & \\
\hline & $\begin{array}{l}\text { The provider organizations, in turn, market the value proposition to their cus- } \\
\text { tomers (i.e., they take on the Service Provider role) }\end{array}$ & \\
\hline & $\begin{array}{l}\text { The provider organizations with the Service Provider role can offer innovative } \\
\text { services with minimal effort for new service development }\end{array}$ & \\
\hline & $\begin{array}{l}\text { The IT provider organization often follows a platform approach to provide } \\
\text { customizable solutions for different provider organizations using reusable } \\
\text { building blocks }\end{array}$ & \\
\hline & $\begin{array}{l}\text { Entrepreneurial risk shared between the IT provider organization and the } \\
\text { provider organization (with the Service Provider role) }\end{array}$ & \\
\hline \multirow{4}{*}{$\begin{array}{l}\text { Forward } \\
\text { Integra- } \\
\text { tion }\end{array}$} & $\begin{array}{l}\text { IT provider organization develops, builds, runs, and offers the innovative smart } \\
\text { service system by itself }\end{array}$ & 6 \\
\hline & $\begin{array}{l}\text { This actor covers most of the relevant roles through internal resources and } \\
\text { competencies }\end{array}$ & \\
\hline & The actor may target markets of former customers & \\
\hline & Entrepreneurial risk is at the IT provider organization & \\
\hline
\end{tabular}


project 9, a manufacturer of industrial doors developed a remote support service for its service department together with a digital business solution provider (Fig. 4).

The White Label Solution pattern reflects an approach where IT provider organizations build innovative solutions on their own initiative to address a market potential that they identified. However, they do offer this service directly to the target customer, i.e., they are not the provider organization. Instead, they offer their solution to other actors, who are already active in the target markets. These provider organizations first assume the role of Project Sponsors to become Service Providers later. The provider organization and the IT provider organization share the role of the Digital Innovator, as they configure and customize the white label solution together. Examples include the energy distribution control service in project 1 (Fig. 5), the diabetes prevention app in project 2 , and the smart parking service in project 5 .

The fourth pattern called Forward Integration goes even further, as the actor with strong IT resources and competencies does not only develop the smart service system on its own but also markets it to the target customers. The energy trading service (project 6) represents such a constellation. As Fig. 6 shows, the ENERGYTRADE organization has the competencies to take on almost any role. The only exception is the provision of a cloud platform, which is sourced from an external actor. Another interesting aspect is that the Digital Innovator role is shared between ENERGYTRADE and its customers. In this case, one potential customer became a strategic development partner to ensure good access to knowledge about the energy trading domain.

Table 6 summarizes the patterns and their characteristics. As shown in the column Projects, we characterized most of the SSSE projects as Provider-driven Development. This pattern reflects a division of work between the involved actors where they largely stick to their original competencies. The provider organization knows its customers and the market and is, therefore, able to come up with new service ideas. In the White Label Solution pattern, firms with strong IT competencies offer a complete or customizable solution to empower other organizations to become providers of smart services. This might be their original business model if they are a startup (project 1) or an application software provider (project 2). However, if the focal actor usually holds the role of the System Integrator, this pattern makes them leave or extend their project-based integration business with time and material pricing. In either case, the provider of a White Label Solution needs to understand the target market very well and takes a higher risk compared to the Provider-driven Development pattern.

Our sample includes projects where provider organizations changed their business models in the course of smart service innovations. Specifically, projects 5 and 6 are examples of IT providers who shifted from traditional IT offerings to comprehensive value propositions for smart parking and energy trading. While both entered new markets, we considered project 6 as even more advanced as the IT provider organization decided to offer the service themselves and, hence, to take on the role of the Service Provider during Operations, whereas in project 5, the service was offered as a white label solution to enable another actor to have the role of the Service Provider. 


\section{Discussion}

\subsection{Contributions to Research}

With this study, we contribute a set of 17 roles that actors of a service ecosystem can assume in smart service innovation. We further provide a systematization of roles into groups along two dimensions: (1) their relevance for SSSE (Primary and Secondary Roles) and (2) their involvement in either only the Engineering subsystem or both the Engineering and Operations subsystems. Regarding these subsystems, we illustrate the dynamics of role assignments to actors in SSSE projects and give an overview of the various constellations of roles and actors that we found in our sample of 14 SSSE projects. Based on the different constellations, we suggest four smart service innovation patterns that help us understand how very different actors of service ecosystems can use their agency, creativity, and strategic intent to innovate with smart service systems. We developed this set of contributions inductively based on the empirical data gathered through expert interviews.

This study yields important merits to research on smart service systems. It has been criticized that they "have mainly been envisaged from a practical and descriptive angle" and that there is "a clear priority for theoretical and empirical future research" on smart service systems (Djellal and Gallouj 2018, p. 17). Moreover, our study takes up the research priority of "leveraging technology to advance service" as put forward by Ostrom et al. (2015, p. 143) who suggest, amongst others, to examine "how the Internet of Things and smart services can enhance the customer experience and influence relationships between customers and service providers" (Ostrom et al. 2015, p. 143). However, while Ostrom et al. (2015, p. 143) mostly emphasize the impact of technology on "customer-company relationships", we ground our work in S-D logic and take the perspective of A2A networks that refrains from assigning narrow and predesignated roles to actors. Based on empirical insights from SSSE projects in our study, we contend that such a perspective is more appropriate to understand technology as a "game changer" that leads to "profound changes in customer experience and value cocreation; front-stage and backstage service provision; and service organizations, networks, and service ecosystems." (Ostrom et al. 2015, p. 145).

As regards S-D logic, in particular, our conceptualization of roles offers a finer level of granularity of understanding roles in service ecosystems when focusing on smart service innovation. While the original S-D logic can be (mis)interpreted as being agnostic of distinct actor roles when all actors are uniformly conceptualized as resource integrators and co-creators of value (Vargo and Lusch 2016), Ekman et al. (2016) already made a distinction between inactive, passive and active as well as between provider and beneficiary roles that service ecosystem actors can assume "fluidly" (Ekman et al. 2016, p. 1), i.e., flexibly and simultaneously. By conceptualizing the contributions of actors into 17 distinct roles that we found relevant to smart service innovation, we went one step further and decreased the level of abstraction, which has been argued to be necessary to transfer theoretical perspectives on service ecosystems into actionable insights (Senn and Bruhn 2019). By decreasing the level of abstraction, we particularly intended to provide better de- 
scriptions and explanations of the specific states of service ecosystem structures and changes to institutional arrangements when digital technologies become "the fundamental source of strategic benefit" (Vargo and Lusch 2016, p. 8) as the fundamental premise (FP) 4 of S-D logic would put it. While our set of roles certainly is not "truly" generic (Ekman et al. 2016, p. 2) anymore, the roles are still grounded in S-D logic as we derived them based on the resources and competencies that actors bring into the exchange relationships of service ecosystems. Moreover, our results indicate that it takes multiple actors (more than only one or two) and hence a macrocontext perspective (Chandler and Vargo 2011) with diverse roles to "actualize the potentiality of technology" (Vargo and Lusch 2016, p. 19) that smart service systems entail. A key reason for this can be seen in the "higher level of complexity in the process of endogenization or incorporation of technology in services" as smart service systems exhibit the "highest degree of [technology] infusion." (Djellal and Gallouj 2018, p. 16) Our empirical insights and the derived set of roles reflect this complexity of technology infusion in service ecosystems very well and, at the same time, point to the limits of too abstract role concepts that were suggested in previous studies. We thus contend that our more fine grained level of role conceptualizations helps in better understanding and explaining how actors "evolve from focusing on dyadic management of their relationships with customers to understanding and managing their role and contributions in many-to-many contexts involving value networks and service ecosystems, in which service provider-customer boundaries are blurring and multiple forms of service provision, by multiple network players, are possible." (Ostrom et al. 2015, p. 145).

When making sense of our empirical data, we adopted the latest contributions that conceptualize service innovation with a foundation in S-D logic. In particular, we referred to the structuration of the service innovation framework by Edvardsson et al. (2018) and added to the empirical validity of it. In particular, we did this in a context that is closely linked to the IoT, which was explicitly mentioned by Edvardsson et al. (2018) as one field of service innovation where it could serve as a conceptual foundation. The structuration of the service innovation framework integrates agencydriven and structure-driven concepts with states of the service innovation process. While the agency-driven concepts helped us in conceptualizing our set of roles, we applied the states of the service innovation process (initiating, realizing, and outcoming) and structure-driven concepts to illustrate the dynamics and patterns of role assignments. In particular, our findings support that "service innovation often takes place in cooperation between several actors contributing a wide range of resources." (Edvardsson et al. 2018, p. 100) The smart service innovation patterns that we derived further support the assumption that the "actors have different reasons to engage in innovative value co-creation" (Edvardsson et al. 2018, p. 100).

Other rather fine-grained models of roles in ecosystems have recently been suggested in technology-focused research fields, which can be considered adjacent to smart service systems. However, these do not focus on service innovation processes and the involvement of multiple actors in SSSE projects. They also provide rather static perspectives on ecosystems, while we were able to also illustrate the dynamics of roles during the service innovation process. For instance, the Passau Cloud Computing Ecosystem Model (PaCE) proposed by Floerecke et al. (2020) 
addresses the realm of cloud computing on a market level. Although our model addresses innovation processes, and not markets, some of the roles are similar, as smart service systems are often operated in cloud environments. For example, our Cloud Platform Provider role is similar to the Platform Provider in PaCE. Other similarities exist between Application Service Provider and Application Provider, and Data Center Operator and Infrastructure Provider. PaCE also proposes the roles of Hardware Developer and Network Operator, which are related to our Hardware Supplier and Connectivity Provider roles, however with relation to different types of hardware and connectivity. Finally, our Service Operator is roughly equivalent to PaCE's Managed Service Provider. In summary, PaCE is more differentiated in cloud-related roles than our model, while our set includes roles with a focus on smart service innovation.

While PaCE is a domain-independent model with a specific focus on cloud computing technology, two others are domain-specific. First, the model by Papert and Pflaum (2017) proposes ecosystem roles for IoT-based services in supply chain management. Project 8 of our sample would fit well in this domain, but it is only one SSSE project in the wider set of smart service innovation processes that we analyzed. Their model contains some domain-specific roles such as the Logistics Service Provider which point to the industry scope of their study, while we tried to conceptualize a set of roles that is generic across various industries. Still, a larger number of their roles also shows similarities to our set of roles. Examples include the IoT Platform Operator, Solution Integrator, and Telecommunication Infrastructure Provider. Comparing to our set of roles, the roles given by Papert and Pflaum (2017) tend to be more specific with regards to different technologies that are relevant to the IoT (e.g., IoT Platform Operator, Human-IoT-Interface Provider, and Middleware Provider). They also identify some roles that we did not derive from our interview data, e.g., Financial Intermediary or Research Institution. However, some of those roles seem to rather reflect specific actor types (e.g., Research Institution and Consultancy) than actual roles in our understanding. Our set of roles further comprises roles that we miss in their work, especially the Customer Representative. Second, Riasanow et al. (2020) also present a domain-specific conceptualization of roles from their investigation of the industrial IoT ecosystem (as one of five ecosystems they researched). This domain can also be related to smart service, especially as regards smart service systems in B2B contexts (like e.g., our projects 9, $10,11,12$, and 13). We can again identify roles in their work that are similar to ours. Examples include Cloud Platform Provider, Manufacturer/OEM, Sensor- \& Connectivity Provider, and IIoT Solution Provider. They also include the Customer in their generic IIoT ecosystem (Riasanow et al. 2020). Comparing with the two domain-specific works by Papert and Pflaum (2017) and Riasanow et al. (2020), our set of roles offers a contribution that is less specific to logistics or industrial settings. The similarities mainly illustrate the relevance of specific technologies from their domains for smart service innovation. At the same time, our set of roles extends the view into the social structures of service innovation as we were less focused on specific technologies or domains and, hence, approached smart service innovation from a broad, sociotechnical perspective. Nevertheless, we infer that our proposed set of roles is compatible with existing research in the areas of business and innovation 
ecosystems as it has intersections with existing models for cloud computing, smart logistics, and Industrial IoT. We consider these different perspectives on roles and ecosystems as complementary. Considering and integrating ecosystem models from different domains can be beneficial for academics and practitioners alike as it enables the planning, description, and analysis of complex structures that go across traditional industry boundaries. However, it is necessary to compare the role definitions in detail to identify potential differences even of roles with identical labels.

The identified smart service innovation patterns are actor-role constellations that describe certain strategic approaches to service innovation. Previous research has identified service innovation patterns that distinguish between Supplier-dominated Innovation, Innovation in Services, Client-Led Innovation, Innovation through Services, and Paradigmatic Innovation (den Hertog 2000). The first three patterns refer to the contributions of three types of actors: suppliers, the service firm, and the client firm, which are similar to the actor types that we defined in our study. The other two follow a different and superordinate rationale. We offer a conceptualization that is consequently derived from analyzing different roles of actors (and not only actors), i.e., actor-role constellations that reflect the required resources and competencies for smart service innovation. Furthermore, we provide a fresh perspective on service innovation patterns through the consideration of digital technologies as key sources of innovation.

Our empirical insights into real-world SSSE projects further inform ongoing discussions on approaches and methods for service systems engineering (Böhmann et al. 2014; Beverungen et al. 2018). In particular, we were able to identify characteristics of recombinant service system engineering (Beverungen et al. 2018) in our sample of SSSE projects, as the actors reused and recombined existing resources, and digital components in particular, for the realization of new value propositions. Examples are manifold and include the reuse of a ticketing app, which was adapted to additionally sell "charging tickets" for electrical vehicles (project 3), the reuse of an existing app for diabetes prevention as part of a health insurance service portfolio (project 2), the integration of various applications for ticketing, travel information, and subscription processing in public transport (project 7). Two of our service innovation patterns, that is, White Label Solution and Forward Integration, further illustrate that reusable digital resources are deliberately build up by actors in order to enable other actors or the actors themselves for recombinant service system engineering. In project 5, for instance, GLOBALSYS designed the smart parking service platform in a way that it can be reused for other cities. These patterns also emphasize the relevance of digital platforms for smart service systems, which is underlined by our conceptualization of the Cloud Platform Provider role. Platforms can be interpreted as a key driver for reducing time-to-market and technical complexity through the reuse of functionality and recombination of existing service components. However, platforms can also create strategic dependencies and reduce competitive advantages through standardization (Hevner and Malgonde 2019), at least for some actors in the service ecosystem like actors that traditionally assumed the Service Provider role. While some actors used platforms as part of their technical design to reduce development costs and simplify operations (projects 6 and 9), ENERGY- 
PLAT followed this approach consequently by becoming a platform provider itself (project 1).

\subsection{Limitations}

Due to the qualitative-empirical and exploratory character of our study, the following limitations must be considered. First, our conceptualization of roles in SSSE projects is grounded in data from only 14 expert interviews. While we achieved to interview experts from a broad range of different SSSE projects in diverse settings, these can neither be considered comprehensive nor representative for smart service innovation in general. Investigating further examples of smart service innovation processes and going beyond the realizing state of such processes, might lead to the identification of additional roles. In particular, the outcoming state of service innovation and, hence, the Operations subsystem was not in our scope. Future research will likely identify further roles that are specifically relevant to ongoing operations of smart service systems as well as the market diffusion and scaling up of value propositions. Second, most of the experts represented IT companies, which were contracted by other actors holding the Project Sponsor role (and aiming at the Service Provider role in the Operations subsystem). Thereby, we were able to ensure a high likelihood that our sample of experts can truly report on collaborative multi-actor project settings. At the same time, this might have introduced a bias towards such settings, where service provider organizations rely on external partners. Third, we only interviewed one expert per project, which limits the available information to her/his single, personal perspective. Therefore, it is likely that especially in large and complex ecosystems, only partial structures could be revealed. Fourth, the proposed roles resulted from our subjective interpretation of the interview data. Although we discussed the definition of roles intensively with all three researchers involved, other researchers might have come to a different conceptualization of roles. Fifth, we were not able to assess the influence of certain actor-role constellations on the overall (perceived) success of the project or even the operating smart service system later on. Most SSSE projects in our sample were in the late stages of the Engineering subsystem or the early stages of market tests. Therefore, we recommend investigating them again at a later point in time to gain insights into the influence of the project setup on project success. These limitations imply that our results should not be conceived as a normative set of roles in the sense of common, good, or best practices.

\subsection{Practical Implications}

The practical implications of our findings relate to innovation management, project management, and strategic issues. First, our results show that smart service innovation takes place through the collaboration of multiple actors, who form networks or become part of service ecosystems. We conclude that establishing, analyzing, and managing such networks is of high importance, especially for the service provider organization as the focal actor. Correspondingly, innovation management at a service firm is not only about developing and realizing new value propositions (with an output perspective) anymore, but increasingly involves network management ac- 
tivities. To better accomplish these activities, our proposed set of roles helps to describe current and future network constellations required for the realization of smart service systems. The set of roles also allows us to describe increasingly complex and dynamic networks, e.g., when there are multiple target customer groups, even including the provider itself.

Regarding project management, our proposed set of roles can be used as a reference to identify the roles and contributions that might be needed for an SSSE project and whether these can be sourced internally or hired externally. Furthermore, the complexity of project setups in our sample shows that efficient measures for managing the collaboration are needed. Strategically, the organization with the Service Provider role must decide upon which of the required skills, knowledge, and services it wants to build up internally and which ones are to be sourced externally. In this regard, intellectual property rights also must be considered, e.g., agreements on the non-disclosure of business ideas, technical concepts, and other potential sources of competitive advantage. As a starting point, the proposed smart service innovation patterns might help to assess the position of an actor in the ecosystem and identify potential strategic dependencies as well as options on how to organize innovation with a given set of organizational resources and competencies. Additionally, the set of roles can help to identify different and conflicting strategic directions of partners that might have to be aligned, e.g., when actors with the Cloud Platform Provider role rely on usage fees and aim to standardize and scale up their offering across multiple A2A networks while the actor with the Service Provider role intends to provide a customer-individual service.

\section{Conclusions and Outlook}

The purpose of this article was to investigate actor-role constellations in service innovation processes that aim at developing new value propositions through smart service systems. We did this through a qualitative-empirical interview study with a theoretical grounding in S-D logic. This article suggests that the development of smart service systems is a collaborative effort of multiple actors with complementary resources and competencies. We further assumed that actors could hold different roles during service innovation processes and especially in SSSE projects. In particular, we were interested in the roles that are assumed by the multiple actors who are involved in SSSE projects. We further tried to identify patterns of smart service innovation by comparing the different actor-role constellations of SSSE projects.

Our empirical data confirmed that all investigated projects required the collaboration of multiple actors, that is, an inter-organizational collaboration that goes way beyond common dyadic perspectives of a service provider and a customer. We developed a set of 17 roles that reflect the required resources and competencies of actors who engage in the development of smart service systems. Our proposed set of roles extends existing theoretical and empirical knowledge about smart service systems through an abstraction of resources and competencies that are relevant in SSSE projects. These roles can be applied to describe and explain why and how larger sets of actors in service ecosystems integrate and reconfigure complementary resources 
and competencies during smart service innovation processes. We found that actors can assume different roles and that roles can be assumed by and be spread across various actors. Through the analysis of such different actor-role constellations that we found in our interview data, we also identified four patterns of smart service innovation. These reflect different institutional arrangements within service ecosystems and help to illustrate the variety of strategies that can be followed by actors.

With our contributions, we aim to advance the understanding of smart service systems and stimulate future research, especially as regards the collaborative engineering through multiple actors in service ecosystems. Practitioners already benefit from a lexicon of roles that can help to express the different needs of resources and competencies for their projects. Furthermore, the identified smart service innovation patterns help to better understand the strategic dependencies between actors and can support decision-making as regards the future development of core competencies that can be of superior value to the actor itself and other beneficiaries. Researchers might use our results as an inspiration and starting point to further investigate the dynamics and service-for-service exchanges of A2A networks where digital technologies invoke changes to institutional arrangements. In particular, we see the need for more detailed analyses of the identified roles to understand their work contributions to SSSE projects, their strategic intents, and their positions in service ecosystems even better. At the same time, it is not only about contributions, but also benefits from being part of SSSE projects. Hence, the typology of roles by Ekman et al. (2016) could be adapted to provide an additional perspective on the actor-role constellations in SSSE projects. This implies that the different exchange relationships between actors need to be analyzed more thoroughly. Here, role-linkage models in business networks according to Kambil and Short (1994) or value co-creation mechanisms as proposed by Autio and Thomas (2018) could provide appropriate lenses for such analyses. Further research is also necessary to advance method support for service systems engineering (Böhmann et al. 2014; Beverungen et al. 2018) in a way that it sufficiently considers the multi-actor characteristics of SSSE projects. One way of achieving this could be to advance and extend modeling methods for business networks like e3value or REA (Schuster and Motal 2009). At the same time, current service engineering methods hardly consider inter-organizational collaboration, further research is also needed to advance them accordingly (Beverungen et al. 2018; Hagen et al. 2018; Dreyer et al. 2019).

Funding Open Access funding provided by Projekt DEAL.

Open Access This article is licensed under a Creative Commons Attribution 4.0 International License, which permits use, sharing, adaptation, distribution and reproduction in any medium or format, as long as you give appropriate credit to the original author(s) and the source, provide a link to the Creative Commons licence, and indicate if changes were made. The images or other third party material in this article are included in the article's Creative Commons licence, unless indicated otherwise in a credit line to the material. If material is not included in the article's Creative Commons licence and your intended use is not permitted by statutory regulation or exceeds the permitted use, you will need to obtain permission directly from the copyright holder. To view a copy of this licence, visit http://creativecommons.org/licenses/by/4. $0 /$. 


\section{References}

Aaltonen, Kirsi, Tuomas Ahola, and Karlos Artto. 2017. Something old, something new: path dependence and path creation during the early stage of a project. International Journal of Project Management 35:749-762.

Abrell, Thomas, Matti Pihlajamaa, Laura Kanto, Jan vom Brocke, and Falk Uebernickel. 2016. The role of users and customers in digital innovation: insights from B2B manufacturing firms. Information \& Management 53:324-335. Information Technology and Innovation: Drivers, Challenges and Impacts. https://doi.org/10.1016/j.im.2015.12.005.

Adner, Roy. 2017. Ecosystem as structure: an actionable construct for strategy. Journal of Management 43:39-58. https://doi.org/10.1177/0149206316678451.

Allmendinger, Glen, and Ralph Lombreglia. 2005. Four strategies for the age of smart services. Harvard Business Review 83:131.

Autio, Erkko, and Llewellyn D.W. Thomas. 2018. Ecosystem value co-creation. Academy of Management Proceedings 2018:15913. https://doi.org/10.5465/AMBPP.2018.15913abstract.

Avelino, Flor, and Julia M. Wittmayer. 2016. Shifting power relations in sustainability transitions: a multiactor perspective. Journal of Environmental Policy \& Planning 18:628-649.

Barrett, Michael, Elizabeth Davidson, Jaideep Prabhu, and Stephen L. Vargo. 2015. Service innovation in the digital age: key contributions and future directions. MIS quarterly 39:135-154.

Beverungen, Daniel, Christoph F. Breidbach, Jens Poeppelbuss, and Virpi Kristiina Tuunainen. 2019a. Smart service systems: an interdisciplinary perspective. Information Systems Journal 29:1201-1206. https://doi.org/10.1111/isj.12275.

Beverungen, Daniel, Hedda Lüttenberg, and Verena Wolf. 2018. Recombinant service systems engineering. Business \& Information Systems Engineering 60:377-391. https://doi.org/10.1007/s12599-0180526-4.

Beverungen, Daniel, Oliver Müller, Martin Matzner, Jan Mendling, and Jan Vom Brocke. 2019b. Conceptualizing smart service systems. Electronic Markets 29:7-18. https://doi.org/10.1007/s12525-0170270-5.

Böhmann, Tilo, Jan Marco Leimeister, and Kathrin Möslein. 2014. Service systems engineering. Business \& Information Systems Engineering 6:73-79. https://doi.org/10.1007/s12599-014-0314-8.

Boukhris, Aida, and Albrecht Fritzsche. 2019. What is smart about services? Breaking the bond between the smart product and the service. In Proceedings of the 27th European Conference on Information Systems. ECIS 2019.

Breidbach, Christoph F., and Paul P. Maglio. 2016. Technology-enabled value co-creation: an empirical analysis of actors, resources, and practices. Industrial Marketing Management https://doi.org/10. 1016/j.indmarman.2016.03.011.

Chandler, J.D., and S.L. Vargo. 2011. Contextualization and value-in-context. Marketing Theory 11:35.

Chowdhury, Soumitra, Darek Haftor, and Natallia Pashkevich. 2018. Smart product-service systems (smart PSS) in industrial firms: a literature review. Procedia CIRP 73:26-31. https://doi.org/10.1016/j.procir. 2018.03.333.

Dedehayir, Ozgur, Saku J. Mäkinen, and J. Roland Ortt. 2018. Roles during innovation ecosystem genesis: a literature review. Technological Forecasting and Social Change 136:18-29. https://doi.org/10.1016/ j.techfore.2016.11.028.

Demirkan, Haluk, Charlie Bess, Jim Spohrer, Ammar Rayes, Don Allen, and Yassi Moghaddam. 2015. Innovations with smart service systems: analytics, big data, cognitive assistance, and the Internet of everything. Communications of the Association for Information Systems https://doi.org/10.17705/ 1CAIS.03735.

Djellal, Faridah, and Faïz Gallouj. 2018. Fifteen challenges for service innovation studies. In A research agenda for service innovation, ed. Faïz Gallouj, Faridah Djellal, 1-26. Cheltenham: Edward Elgar.

Dreyer, Sonja, Daniel Olivotti, Benedikt Lebek, and Michael H. Breitner. 2019. Focusing the customer through smart services: a literature review. Electronic Markets 29:55-78. https://doi.org/10.1007/ s12525-019-00328-z.

Edvardsson, Bo, and Bård Tronvoll. 2013. A new conceptualization of service innovation grounded in S-D logic and service systems. International Journal of Quality and Service Sciences 5:19-31. https://doi. org/10.1108/17566691311316220.

Edvardsson, Bo, Bård Tronvoll, and Lars Witell. 2018. An ecosystem perspective on service innovation. A research agenda for service innovation. Cheltenham: Edward Elgar. 
Eisenhardt, Kathleen M. 1989. Building theories from case study research. The Academy of Management Review 14:532-550. https://doi.org/10.2307/258557.

Ekman, Peter, Randle D. Raggio, and Steven M. Thompson. 2016. Service network value co-creation: defining the roles of the generic actor. Industrial Marketing Management 56:51-62.

Floerecke, Sebastian, and Franz Lehner. 2016. Cloud computing ecosystem model: refinement and evaluation. In Proceedings of ECIS 2016. Istanbul, Turkey.

Floerecke, Sebastian, Franz Lehner, and Sebastian Schweikl. 2020. Cloud computing ecosystem model: evaluation and role clusters. Electronic Markets https://doi.org/10.1007/s12525-020-00419-2.

Hagen, Simon, Friedemann Kammler, and Oliver Thomas. 2018. Adapting product-service system methods for the digital era: requirements for smart PSS engineering. In Customization 4.0 Springer proceedings in business and economics, Vol. 97, ed. Stephan Hankammer, Kjeld Nielsen, Frank T. Piller, Günther Schuh, and Ning Wang, 87-99. Cham: Springer. https://doi.org/10.1007/978-3-319-775562_6.

den Hertog, Pim. 2000. Knowledge-intensive business services as co-producers of innovation. International Journal of Innovation Management https://doi.org/10.1142/S136391960000024X.

Hevner, Alan, and Onkar Malgonde. 2019. Effectual application development on digital platforms. Electronic Markets https://doi.org/10.1007/s12525-019-00334-1.

Janowicz-Panjaitan, Martyna, and Niels G. Noorderhaven. 2009. Trust, calculation, and Interorganizational learning of tacit knowledge: an organizational roles perspective. Organization Studies 30:1021-1044. https://doi.org/10.1177/0170840609337933.

Jonas, Julia M., and Angela Roth. 2017. Stakeholder integration in service innovation-an exploratory case study in the healthcare industry. International Journal of Technology Management https://doi. org/10.1504/IJTM.2017.082358.

Jonas, Julia M., Angela Roth, and Kathrin M. Möslein. 2016. Stakeholder integration for service innovation in German medium-sized enterprises. Service Science 8:320-332.

Jussen, Philipp, Jan Kuntz, Roman Senderek, and Benedikt Moser. 2019. Smart service engineering. In Procedia CIRP. 11th CIRP Conference on Industrial Product-Service Systems. Vol. 83, 384-388. https://doi.org/10.1016/j.procir.2019.04.089.

Kambil, Ajit, and James E. Short. 1994. Electronic integration and business network redesign: a roleslinkage perspective. Journal of Management Information Systems 10:59-84. https://doi.org/10.1080/ 07421222.1994 .11518020$.

Knight, Louise, and Christine Harland. 2005. Managing supply networks: organizational roles in network management. European Management Journal 23:281-292. https://doi.org/10.1016/j.emj.2005. 04.006 .

Lusch, Robert F., and Satish Nambisan. 2015. Service innovation: a service-dominant logic perspective. MIS quarterly 39:155-175.

Lusch, Robert F., and Stephen L. Vargo. 2006. Service-dominant logic: reactions, reflections and refinements. Marketing Theory 6:281-288. https://doi.org/10.1177/1470593106066781.

Nambisan, Satish. 2013. Information technology and product/service innovation: a brief assessment and some suggestions for future research. Journal of the Association for Information Systems 14:1.

National Science Foundation. 2014. Partnerships for innovation: building innovation capacity (PFI:BIC). https://www.nsf.gov/pubs/2013/nsf13587/nsf13587.htm

Ostrom, Amy L., A. Parasuraman, David E. Bowen, Lia Patrício, and Christopher A. Voss. 2015. Service research priorities in a rapidly changing context. Journal of Service Research 18:127-159. https:// doi.org/10.1177/1094670515576315.

Papert, Marcel, and Alexander Pflaum. 2017. Development of an ecosystem model for the realization of Internet of things (IoT) services in supply chain management. Electronic Markets 31:306. https://doi. org/10.1007/s12525-017-0251-8.

Porter, Michael E., and James E. Heppelmann. 2015. How smart, connected products are transforming companies. Boston, MA: HBR.

Rese, Alexandra, Hans-Georg Gemünden, and Daniel Baier. 2013. 'Too many cooks spoil the broth': key persons and their roles in inter-organizational innovations. Creativity and Innovation Management 22:390-407. https://doi.org/10.1111/caim.12034.

Riasanow, Tobias, Lea Jäntgen, Sebastian Hermes, Markus Böhm, and Helmut Krcmar. 2020. Core, intertwined, and ecosystem-specific clusters in platform ecosystems: analyzing similarities in the digital transformation of the automotive, blockchain, financial, insurance and IIoT industry. Electronic Markets https://doi.org/10.1007/s12525-020-00407-6. 
Schuster, Rainer, and Thomas Motal. 2009. From e3-value to REA: modeling multi-party E-business collaborations. In 2009 IEEE Conference on Commerce and Enterprise Computing, 202-208. IEEE. https://doi.ieeecomputersociety.org/10.1109/CEC.2009.58

Senn, Tim, and Manfred Bruhn. 2019. Digitalisierte Service Ecosysteme - Entscheidungstatbestände und Forschungsbedarf. In Kooperative Dienstleistungen: Spannungsfelder zwischen Service Cooperation und Service Coopetition Forum Dienstleistungsmanagement., ed. Manfred Bruhn, Karsten Hadwich, 201-226. Wiesbaden: Springer. https://doi.org/10.1007/978-3-658-26389-8_10.

Sklyar, Alexey, Christian Kowalkowski, David Sörhammar, and Bård Tronvoll. 2019a. Resource integration through digitalisation: a service ecosystem perspective. Journal of Marketing Management https://doi.org/10.1080/0267257X.2019.1600572.

Sklyar, Alexey, Christian Kowalkowski, Bård Tronvoll, and David Sörhammar. 2019b. Organizing for digital servitization: a service ecosystem perspective. Journal of Business Research 104:450-460. https:// doi.org/10.1016/j.jbusres.2019.02.012.

Storbacka, Kaj, Roderick J. Brodie, Tilo Böhmann, Paul P. Maglio, and Suvi Nenonen. 2016. Actor engagement as a microfoundation for value co-creation. Journal of Business Research https://doi.org/ 10.1016/j.jbusres.2016.02.034.

Sydow, Jörg. 2009. Path dependencies in project-based organizing: evidence from television production in Germany. Journal of Media Business Studies 6:123-139.

Sydow, Jörg, and Timo Braun. 2018. Projects as temporary organizations: an agenda for further theorizing the interorganizational dimension. International Journal of Project Management 36:4-11.

Vargo, Stephen L., and Robert F. Lusch. 2004. Evolving to a new dominant logic for marketing. Journal of Marketing 68:1-17. https://doi.org/10.1509/jmkg.68.1.1.24036.

Vargo, Stephen L., and Robert F. Lusch. 2008. Service-dominant logic. Journal of the Academy of Marketing Science 36:1-10. https://doi.org/10.1007/s11747-007-0069-6.

Vargo, Stephen L., and Robert F. Lusch. 2011. It's all B2B...and beyond: toward a systems perspective of the market. Industrial Marketing Management 40:181-187. Special Issue on Service-Dominant Logic in Business Markets. https://doi.org/10.1016/j.indmarman.2010.06.026.

Vargo, Stephen L., and Robert F. Lusch. 2016. Institutions and axioms: an extension and update of service-dominant logic. Journal of the Academy of Marketing Science 44:5-23. https://doi.org/10.1007/ s11747-015-0456-3.

Vargo, Stephen L., Robert F. Lusch, Melissa Archpru Akaka, and Yi He. 2010. Service-dominant logic. In Review of marketing research, ed. Naresh K. Malhotra, 125-167. Bingley: Emerald Group. https:// doi.org/10.1108/S1548-6435(2009)0000006010.

Wolf, Verena. 2020. Understanding smart service systems transformation-A socio-technical perspective. In ECIS 2020 Research-in-Progress Papers.

Wuenderlich, Nancy V., Kristina Heinonen, Amy L. Ostrom, Lia Patricio, Rui Sousa, Chris Voss, and Jos G.A.M. Lemmink. 2015. "Futurizing” smart service. Journal of Services Marketing 29:442-447. https://doi.org/10.1108/JSM-01-2015-0040.

Yin, Robert K. (ed.). 2016. Qualitative research from start to finish. New York: The Guilford Press

Yin, Robert K. 2018. Case study research and applications. Design and methods. Los Angeles: SAGE Publications.

Publisher's Note Springer Nature remains neutral with regard to jurisdictional claims in published maps and institutional affiliations. 